Article

\title{
Integration of Terrestrial and Drone-Borne Hyperspectral and Photogrammetric Sensing Methods for Exploration Mapping and Mining Monitoring
}

\author{
Moritz Kirsch 1,* (D), Sandra Lorenz ${ }^{1}$, Robert Zimmermann ${ }^{1}$ (D), Laura Tusa ${ }^{1}$, Robert Möckel ${ }^{1}$, \\ Philip Hödl ${ }^{1}$, René Booysen ${ }^{1,2}$, Mahdi Khodadadzadeh ${ }^{1}$ and Richard Gloaguen ${ }^{1}$ (D) \\ 1 Helmholtz-Zentrum Dresden-Rossendorf, Helmholtz Institute Freiberg for Resource Technology, \\ Chemnitzer Straße 40, 09599 Freiberg, Germany; s.lorenz@hzdr.de (S.L.); r.zimmermann@hzdr.de (R.Z.); \\ l.tusa@hzdr.de (L.T.); r.moeckel@hzdr.de (R.M.); p.hoedl@hzdr.de (P.H.); r.booysen@hzdr.de (R.B.); \\ m.khodadadzadeh@hzdr.de (M.K.); r.gloaguen@hzdr.de (R.G.) \\ 2 School of Geoscience, University of the Witwatersrand, 1 Jan Smuts Avenue, \\ Braamfontein, Johannesburg 2000, South Africa \\ * Correspondence: m.kirsch@hzdr.de; Tel.: +49-351-260-4439
}

Received: 20 July 2018; Accepted: 24 August 2018; Published: 28 August 2018

\begin{abstract}
Mapping lithology and geological structures accurately remains a challenge in difficult terrain or in active mining areas. We demonstrate that the integration of terrestrial and drone-borne multi-sensor remote sensing techniques significantly improves the reliability, safety, and efficiency of geological activities during exploration and mining monitoring. We describe an integrated workflow to produce a geometrically and spectrally accurate combination of a Structure-from-Motion Multi-View Stereo point cloud and hyperspectral data cubes in the visible to near-infrared (VNIR) and short-wave infrared (SWIR), as well as long-wave infrared (LWIR) ranges acquired by terrestrial and drone-borne imaging sensors. Vertical outcrops in a quarry in the Freiberg mining district, Saxony (Germany), featuring sulfide-rich hydrothermal zones in a granitoid host, are used to showcase the versatility of our approach. The image data are processed using spectroscopic and machine learning algorithms to generate meaningful 2.5D (i.e., surface) maps that are available to geologists on the ground just shortly after data acquisition. We validate the remote sensing data with thin section analysis and laboratory X-ray diffraction, as well as point spectroscopic data. The combination of ground- and drone-based photogrammetric and hyperspectral VNIR, SWIR, and LWIR imaging allows for safer and more efficient ground surveys, as well as a better, statistically sound sampling strategy for further structural, geochemical, and petrological investigations.
\end{abstract}

Keywords: hyperspectral imaging; Structure-from-Motion (SfM); mineral mapping; virtual outcrops; geology; hydrothermal; UAV; long-wave infrared

\section{Introduction}

Digital outcrop models provide geometrically accurate 3D records of geological exposures over a range of scales (from centimeters to hundreds of meters) that can be used to visualize and analyze lithology and structure (e.g., [1-5]). Usually, the color information of digital outcrops is based on digital photographs, which capture broad bands of the visible part of the electromagnetic spectrum and are not radiometrically corrected, limiting their use. However, hyperspectral imagery, in which every pixel contains a continuous spectrum over a certain wavelength range [6,7], provides a suitable means to remotely map compositional variations in geological formations [8-12]. This is based on the 
fact that for any given material, the amount of radiation that is reflected, absorbed, or emitted is a function of its wavelength, so that minerals have unique spectral signatures (e.g., [13-19]). For the full integration of digital outcrops and infrared spectroscopy, three main aspects remain to be considered:

1. Hyperspectral imagery has recently been integrated into digital outcrops (e.g., [20-25]), but using only hyperspectral data in the visible to near infrared (VNIR) and the shortwave infrared (SWIR) part of the electromagnetic spectrum, which lacks distinctive Si-O bond-related spectral features [26]. Hyperspectral long-wave infrared (LWIR) imaging complements VNIR-SWIR data in the field of mineral mapping, since the molecular vibrations of many rock-forming minerals have characteristic resonant wavelengths in the LWIR part of the electromagnetic spectrum [27]. LWIR hyperspectral sensors have been utilized for the characterization of geologic materials in the laboratory (e.g., [28-32]) and from airborne platforms [33-35], but have only very recently been employed for geological mapping in ground-based mode [36,37].

2. While the potential of combining VNIR, SWIR and LWIR hyperspectral data for geological mapping has been recognized [12,38-40], hyperspectral imagers have been operated from a single platform, usually airborne (e.g., [41,42]). Recently, the Helmholtz Institute Freiberg for Resource Technology started to deploy hyperspectral sensors on the ground [24,37], and on unmanned aerial systems $[43,44]$. This approach allows for higher spatial resolutions (from millimeters to tens of centimeters) and a range of scanning perspectives, which can be advantageous, particularly in areas with steep outcrops and poorly accessible and potentially dangerous terrain.

3. Digital outcrop models are traditionally based on data obtained from laser scanning (e.g., [4,45-47]) or photogrammetric techniques (e.g., [48-52]). Fusion between hyperspectral and 3D outcrop data is mostly based on terrestrial laser scanning (TLS) data (e.g., [20-23,53,54]). TLS can be used to derive highly precise outcrop models (e.g., [48,55-57]), but these are prone to containing data gaps caused by occlusion, particular in areas of high relief. The effect of occlusion can be reduced by obtaining TLS data from multiple scan locations, but this is time-consuming, and can be impeded in areas of restricted accessibility. Airborne laser scanning may supplement TLS, but it requires substantial financial and logistical efforts. Alternatively, 3D outcrop geometry may be reconstructed rapidly, safely, and cost-efficiently by the means of Structure-from-Motion Multi-View Stereo (SfM-MVS, or simply SfM) photogrammetry. Due to the varying image acquisition angles, SfM point clouds based on terrestrial and aerial photographs are less influenced by occlusion, and they can serve as a basis for the fusion of spectral datasets with varied sensor positions.

While there are some aspects that have been covered (e.g., [58-62]), a comprehensive approach to generate geometrically and spectrally accurate digital outcrops from multi-sensor datasets has never been proposed. The objective of this study is to describe a novel acquisition, processing, and interpretation workflow for the combination of ground- or unmanned aerial vehicle (UAV)-based hyperspectral VNIR, SWIR, and LWIR data, and their integration into SfM point clouds. This set of routines can easily be adapted to other hyperspectral sensors, and it is envisaged to increase the efficiency and safety of geological mapping in geoscientific research, mineral exploration, mining, and geohazard monitoring. To demonstrate the workflow, we selected the Naundorf quarry in the Freiberg mining district, Saxony (Germany) as a case study location. The well-exposed and accessible vertical quarry faces combined with the occurrence of (i) compositionally diverse granitoid host rocks and (ii) zones with sulfide mineralization and associated hydrothermal and supergene alteration makes the Naundorf quarry a well-suited target to demonstrate the versatility of our integrative approach. For pre-processing of the hyperspectral data, we use established routines for the correction of e.g., topographic and atmospheric effects [24,43], and validate the results using field observations and a variety of analytical techniques. For post-processing, emphasis is put on simple and fast workflows using both standard and innovative machine learning-based image processing and classification techniques to enable an almost instantaneous discrimination of lithologic domains for more efficient geological fieldwork. 


\section{Case Study}

The Naundorf gravel quarry, located in the state of Saxony, eastern Germany, ca. $30 \mathrm{~km}$ SW of Dresden (Figure 1), was selected as a location for the acquisition of SfM photogrammetric and hyperspectral ground-based VNIR-SWIR and LWIR, as well as UAV-based VNIR datasets. Geologically, the rocks of the quarry belong to the Erzgebirge, a domain of Variscan crystalline basement rocks at the northern margin of the Bohemian Massif [63]. At the quarry, Late Variscan (ca. 325-320 Ma; [64,65]) biotite granites of the Niederbobritzscher Granite (Figure 2A) are cut by a number of faults associated with phyllic hydrothermal alteration (Figure 2B). The orientation of these structures (sub-vertical dip, WNW-ESE and NNE-SSW strike; Figures 1D and 2C) is characteristic for the polymetallic sulphide vein network of the Freiberg mining district, in particular, carbonate- or quartz-bearing $\mathrm{Ag}-\mathrm{Sb}$ veins (eb ore type, i.e., the "edle Braunspat Formation" = noble carbonate formation) and quartz-bearing $\mathrm{As}(-\mathrm{Au})-\mathrm{Zn}-\mathrm{Cu}(-\mathrm{In}-\mathrm{Cd})-\mathrm{Sn}-\mathrm{Pb}-\mathrm{Ag}-\mathrm{Bi}-\mathrm{Sb}$ veins $(\mathrm{kb}$ ore type, i.e., "kiesig-blendige Bleierzformation" = pyritic lead formation), respectively (e.g., [66-68]).

For validation, extensive geological fieldwork was conducted at the Naundorf quarry, including structural measurements, and documentation of the lithology, mineralization, and alteration. For analytical purposes, six hand-sized rock samples were collected at the Naundorf quarry for thin section, X-ray diffraction (XRD), and spectroscopic analysis. The specimens comprise three samples from the host rock (a monzogranite, a mafic enclave of quartz monzonitic composition, and a microgranite) and three samples from hydrothermal zones (altered monzogranite 1 and 2, representing increasing degrees of hydrothermal alteration, and a quartz vein). Although not taken in situ, these samples are considered to be representative of the lithologic variability of the NW part of the quarry, as captured in the hyperspectral scenes. An additional set of three samples was collected in situ for VNIR-SWIR spectral measurements. These samples were taken from the surface of a prominent fault surface exposed in the center of the outcrop containing sulphides and secondary iron minerals. 

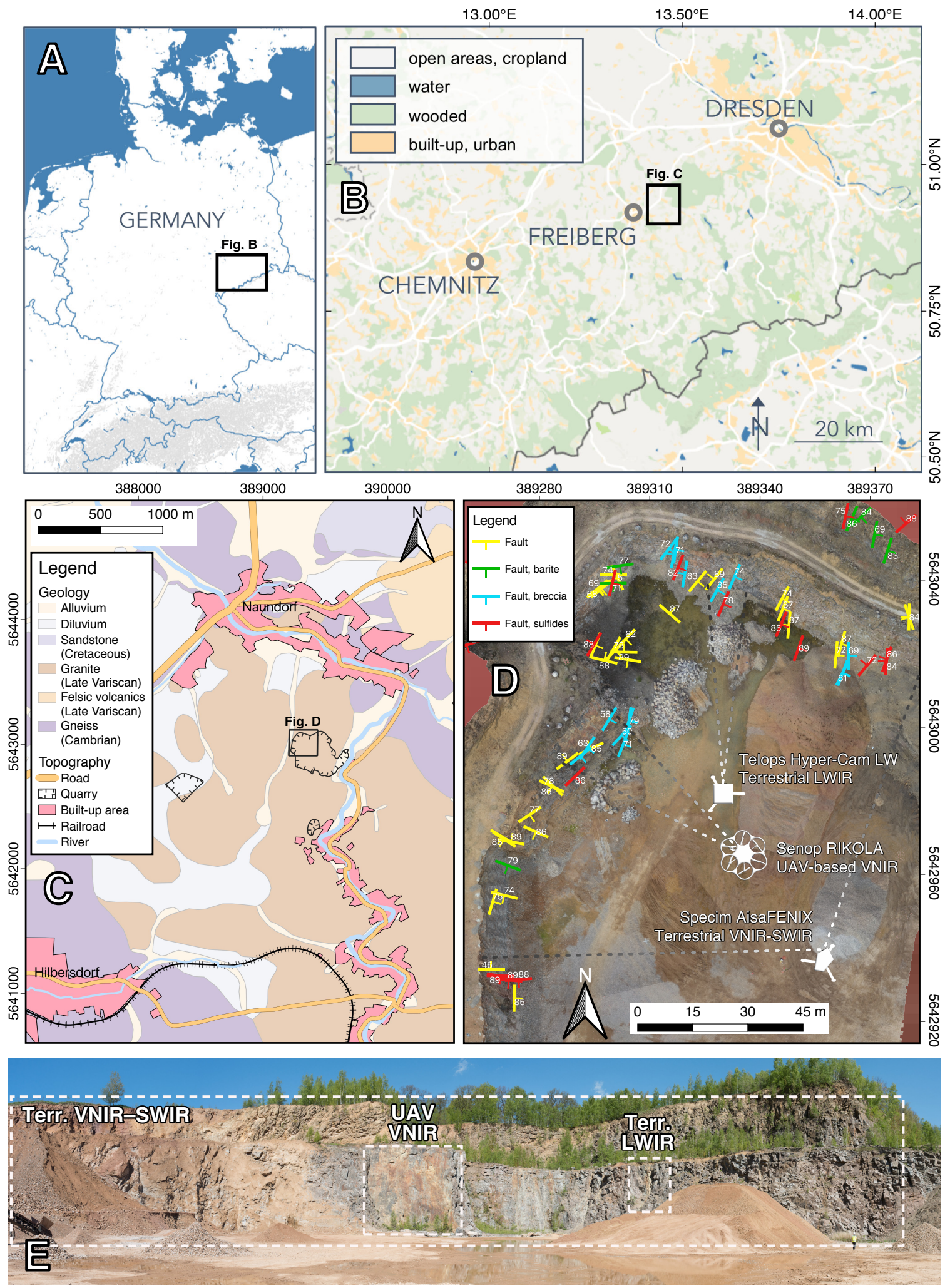

Figure 1. (A-C) Location of the investigated vertical geological outcrop in the Naundorf quarry, eastern Germany. (D) Orthophoto of the NW part of the Naundorf quarry showing scanning positions of the employed hyperspectral sensors, as well as structural field measurements of mineralized faults. (E) Panorama of the investigated outcrop (size ca. $200 \times 40 \mathrm{~m}$ ) in the NW corner of the quarry. Rectangular overlays correspond to the extents of the respective hyperspectral scenes. Person for scale in the bottom right of the image. Abbreviation: Terr.-terrestrial. 

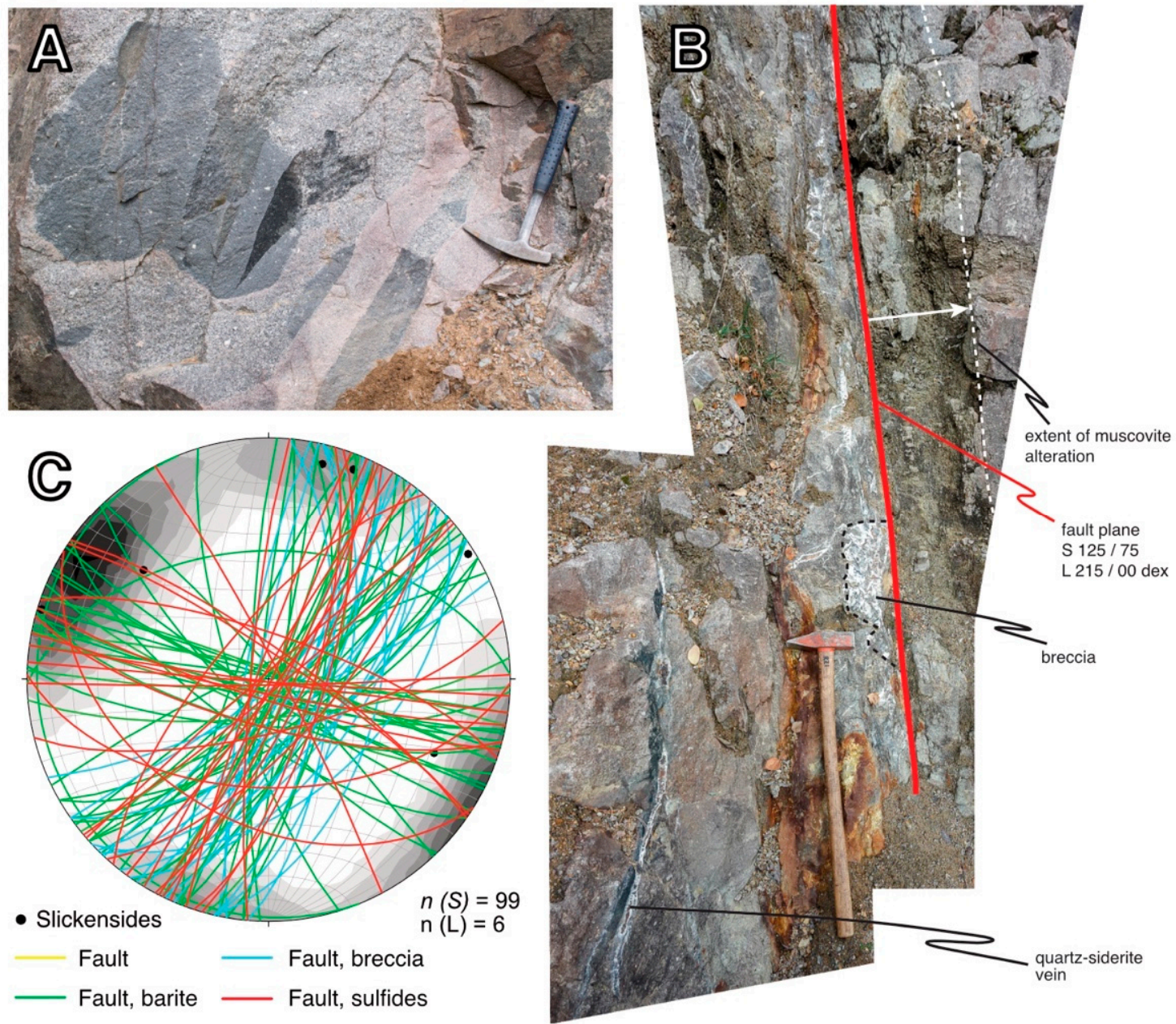

Figure 2. (A) Photo showing the intrusive relationships in granitoid host rocks at the Naundorf quarry. Coarse-grained monzogranite (main lithology) with quartz monzonite enclave (dark blobs) being cut by a microgranitic aplite dike (fine-grained linear structure cutting enclave on the right). (B) Hydrothermally altered fault zone (also captured by terrestrial VNIR-SWIR and LWIR scenes) showing silicification, brecciation, sericitisation, and carbonate precipitation. Hammer handle for scale is $1 \mathrm{~m}$. (C) Stereonet diagram of all faults and hydrothermal veins (dominantly brecciated, sulfide- or barite-bearing) measured in the field. These structures are subvertical and their orientation is typical for polymetallic veins-type deposits in the Freiberg mining district. All stereograms are equal-area, lower-hemisphere projections. Contours are drawn according to the method of [69] using a $3 \sigma$ significance level and a $2 \sigma$ contour interval.

\section{Methods and Materials}

\subsection{Ground-Based VNIR-SWIR Hyperspectral Imaging}

Ground-based hyperspectral outcrop data was acquired in sunny conditions using a tripod-mounted Specim AisaFenix [70] hyperspectral push broom scanner (Tables 1 and 2). The VNIR-SWIR hyperspectral dataset of the Naundorf quarry featured a ca. $130^{\circ}$ swath of the NW vertical quarry wall (Figure 1D,E) and covered all of the first and second benches within that swath at a ground resolution of about $13 \mathrm{~cm}$. 
Table 1. Overview of hyperspectral datasets used in this study. Abbreviations: VNIR-visible to near-infrared; SWIR—shortwave infrared; LWIR—longwave infrared.

\begin{tabular}{ccccccc}
\hline Date & Time & Sensors & Platform & Type & No. of Images & Image Overlap \\
\hline 11 May 2017 & 11:30 AM & VNIR-SWIR & Specim AisaFenix & Terrestrial, push broom & 1 & \\
\hline 19 October 2017 & 1:45 PM & LWIR & Telops Hyper-Cam LW & Terrestrial, frame & 12 & $30 \%$ \\
\hline 24 May 2018 & $12: 45$ PM & VNIR & Senop Rikola & Drone-borne & 2 & $20 \%$ \\
\hline
\end{tabular}

Table 2. Sensor specifications of the Specim AisaFenix VNIR-SWIR hyperspectral camera as given by Specim Spectral Imaging Oy, Oulu, Finland.

\begin{tabular}{ccc}
\hline Wavelength range & VNIR & 380-970 nm \\
& SWIR & $970-2500 \mathrm{~nm}$ \\
\hline Spectral resolution/sampling distance & VNIR & $3.5 \mathrm{~nm} / 1.7 \mathrm{~nm}$ \\
& SWIR & $12 \mathrm{~nm} / 5.7 \mathrm{~nm}$ \\
\hline Number of bands & \multicolumn{2}{c}{624} \\
\hline Field of view (FOV) & $32.3^{\circ}$ & $(384$ detectors $)$ \\
\hline Focal length & \multicolumn{2}{c}{$16.615 \mathrm{~mm}$} \\
\hline Maximum scanning angle & \multicolumn{2}{c}{$130^{\circ}$} \\
\hline Spectral binning & VNIR & 2 \\
& SWIR & 1 \\
\hline
\end{tabular}

The pre-processing of ground-based hyperspectral data followed the workflow presented in [24] and was as follows (Figure 3):

1. Conversion to at-sensor radiance: The first step included dark-current subtraction, followed by image normalization and multiplication of the sensor- and band-specific radiometric calibration data.

2. Optical distortion correction: In this step, sensor-specific optical distortions were corrected for. In case of the Specim AisaFenix scanner, this encompassed fish-eye- and slit-bending effects, which could be removed by applying sensor-specific correction values for each pixel in the field of view (FOV).

3. Conversion to at-sensor reflectance: This conversion was achieved by an empirical line calibration using a white reference panel (Spectralon SRS-99, [71]) placed in the scene with a similar orientation to the target.

4. Orthorectification and georeferencing: A corresponding photogrammetric point cloud (see below) was transformed, projected, and rasterized to represent the viewing angle of the hyperspectral sensor. In case of data acquired with the Specim AisaFenix, a cylindrical projection was used to account for the panoramic imaging geometry of push broom scanners (see [24] for details). The resulting acquisition-specific pseudo-orthophoto contained red-green-blue (RGB) values, original coordination, and sun incidence angles for each rasterized pixel. Subsequently, the hyperspectral image was referenced to the pseudo-orthophoto based on 23 manual tie points that were spread evenly over the entire scene.

5. Conversion to at-target reflectance: The hyperspectral image may be influenced by illumination differences due to topography. These were corrected for by c-factor topographic correction (see [43] for details) based on pixel-specific sun incidence angles, which were determined for each point of the photogrammetric 3D point cloud and stored in each pixel of the created pseudo-orthophoto, as described above. 


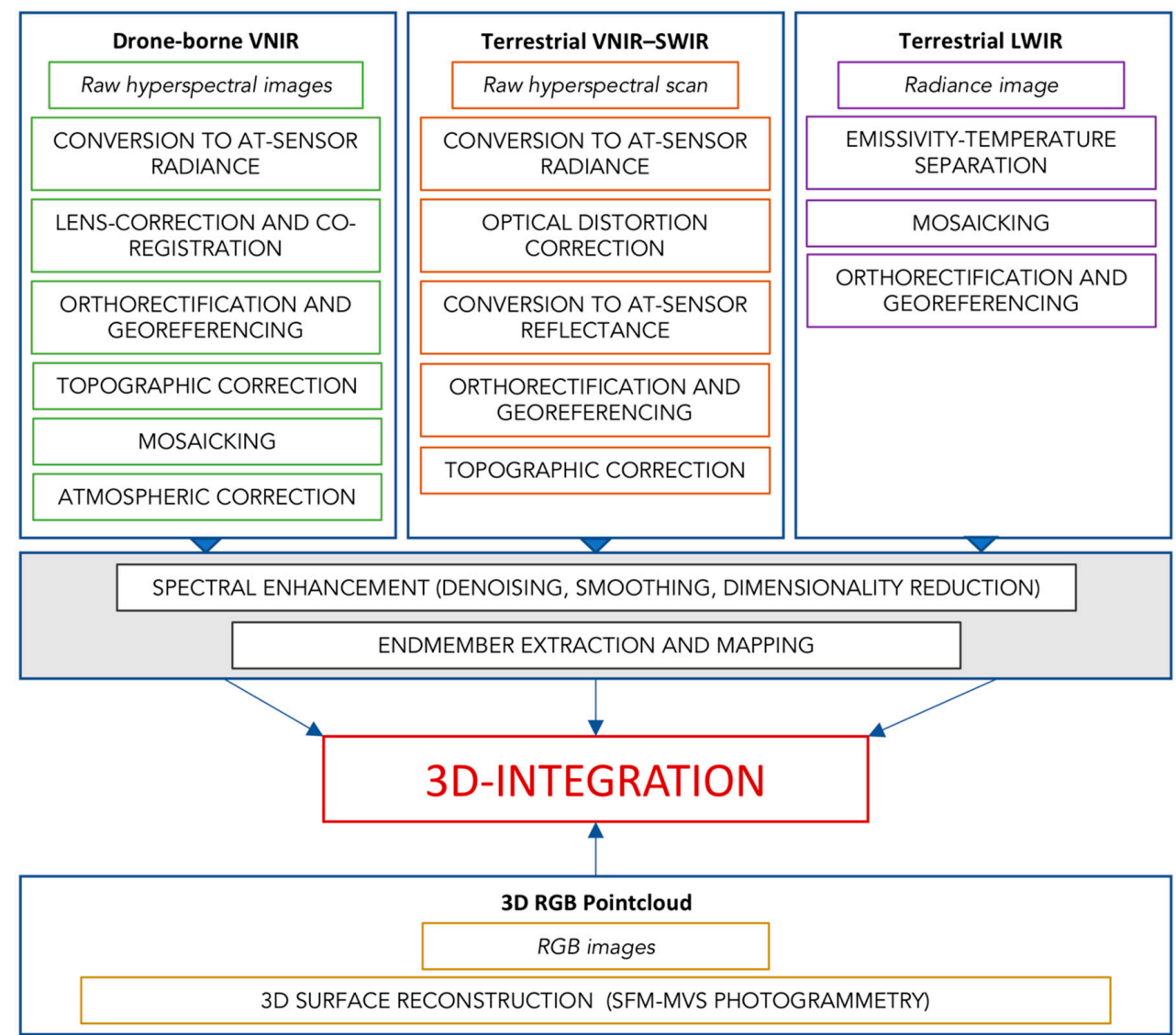

Figure 3. Schematic processing workflow for the integration of VNIR-SWIR-LWIR hyperspectral data and SfM photogrammetric point clouds.

The post-processing of the terrestrial VNIR-SWIR data from the Naundorf quarry included masking of the image to remove vegetation, as well as removal of gravel piles obstructing the view of the outcrop. Vegetation masking was performed based on the normalized difference vegetation index (NDVI). Spectral smoothing was applied based on a minimum noise fraction (MNF, [72]) transformation. Minimum wavelength mapping was used as a simple means to highlight variations in mineral abundances in different absorption bands, such as $\sim 2160-2220 \mathrm{~nm}$ for Al-OH, $\sim 2230-2295 \mathrm{~nm}$ for Fe-OH, 2300-2360 nm for Mg-OH/ $\mathrm{CO}_{3}$ [13-15,73], and 400-950 nm for Fe-oxide, Fe-hydroxide, and Fe-sulphate-hydrate minerals (e.g., [74]). The minimum wavelength maps were generated by using the Hyperspectral Python toolbox (HypPy, e.g., [61,75]) and in-house Python scripts. In minimum wavelength maps, the hue corresponds to the wavelength position of a certain absorption feature, and the color intensity reflects the absorption depth of the feature [61,76]. The classification maps of mineral assemblages were generated using ENVI version 5.1 (Exelis Visual Information Solutions, Boulder, CO, USA) software. First, a MNF transform process was used in order to reduce the dimensionality of the data, followed by the pixel purity index (PPI, [77,78]) in order to determine and locate the purest pixels in the dataset. Subsequently, an endmember extraction was performed using ENVI's n-Dimensional visualizer (N-FINDR, [79]), which allows the visualization of endmember clusters consisting of the purest pixels in an $\mathrm{n}$-dimensional space. The parameter $\mathrm{n}$ represents the number of selected relevant MNF bands, while the coordinates of each point represents the reflectance of a specific pixel in each of the bands. With the selected endmembers, a mineral mapping was performed using ENVI's spectral angle mapper (SAM, [80]), which evaluates the similarity between the image and reference spectra based on their angular distance in $n$ (= number of bands) dimensions. 


\subsection{Ground-Based LWIR Hyperspectral Imaging}

LWIR hyperspectral data were acquired in sunny conditions using a tripod-mounted Telops Hyper-Cam LW [81,82] operated in ground-based mode (Tables 1 and 3). A prominent, ca. $2 \mathrm{~m}$ thick hydrothermal zone surrounded by hybrid granitoid host rocks along the northern wall of the Naundorf quarry was selected for LWIR imaging (Figure 1E). The zone is subvertical (dip azimuth/dip angle of fault plane $=125 / 75^{\circ}$ ) and features disseminated sulfides, massive quartz veins, brecciation, sericitisation, and carbonate precipitation (Figure 2B). Due to the small footprint of a single image frame (Table 3), the area of interest was covered by an array of $3 \times 4$ images individually overlapping by approximately $30 \%$.

Table 3. Sensor specifications of the Telops Hyper-Cam LW thermal hyperspectral camera.

\begin{tabular}{cc}
\hline Image size & $320 \times 256 \mathrm{px}, 67$ spectral bands \\
Field of view (FOV) & $6.4^{\circ} \times 5.1^{\circ}$ (standard lens) \\
Focal length & $86 \mathrm{~mm}($ standard lens) \\
Spectral coverage & $1300-881 \mathrm{~cm}^{-1}(7.7-11.8 \mu \mathrm{m})$ \\
Spectral resolution & 0.25 to $150 \mathrm{~cm}^{-1}$ \\
Imaging distance/footprint & $55 \mathrm{~m} / 6.1 \times 4.9 \mathrm{~m}$ \\
\hline
\end{tabular}

The calibration and pre-processing workflow of the Hyper-Cam data is described in detail in [24] and consisted of the following steps (Figure 3):

1. Conversion to radiance: Immediately after acquisition, the raw interferometer data frame was automatically converted to radiance based on the offset and gain of an internal blackbody calibration. For internal calibration, the device features two blackbodies, the temperatures of which were adjusted to bracket the expected temperature range of the measured scenario to minimize the non-linearity effects of the instrument's response.

2. Temperature-emissivity separation: To achieve the radiometric calibration, a temperature-emissivity separation (TES) was performed using the algorithms of the TES-MATLAB toolbox developed by Telops. A custom-made diffuse reflector (brushed Al-panel, Al 6082 alloy) and a blackbody (Al panel, milled and sprayed with black Würth acrylic lacquer paint) were placed in the scene during acquisition. Whereas the diffuse reflector (high reflectivity, low emissivity) was used to estimate the atmospheric downwelling radiance, the blackbody (high emissivity, low reflectivity) was used to determine the emissivity of the target, which varies according to the temperature-specific Planck function and the atmospheric transmittance between the sensor and target. Other parameters needed for the TES were the emissivities of both reference surfaces (in the Naundorf LWIR scene 0.95 and 0.17, for the blackbody and the reflector, respectively), the panel temperatures, which for the Naundorf LWIR scene were extracted from the brightness-temperature image (blackbody $51.78^{\circ} \mathrm{C}$; diffuse reflector $21.35^{\circ} \mathrm{C}$, measured at the water vapor line at $282.15 \mathrm{~K}$ ), and the ambient air temperature $\left(26.7^{\circ} \mathrm{C}\right.$, measured with a digital thermometer). The TES returns both a temperature image and the spectral emissivity data cube.

3. Image stitching: In order to stitch the individual image frames together to a mosaic, the automatic key point detection and matching workflow from [43] was successfully adapted to the LWIR data. The data cubes were automatically matched using a looping trial-and-error procedure, which eliminated the need for prior image sorting. The created mosaic was subsequently orthorectified and referenced to a scene-specific pseudo-orthophoto using 22 manually collected tie points.

Before image interpretation, the calibrated LWIR hypercube was masked to remove stitching edges of the image mosaic and the calibration panels in the scene. Subsequently, a spectral subsetting was performed to eliminate atmospheric bands, and smoothed using MNF smoothing. Apart from algorithms used for the ground-based VNIR-SWIR dataset, such as SAM, image processing for the LWIR scene is based on linear spectral unmixing (LSU, e.g., [83-85], which 
estimates the relative contributions (abundances) of a defined set of endmembers to each image pixel. Moreover, the LWIR data was processed using a technique based on the random forest (RF, [86]) classifier. In this technique, endmembers were first extracted from the scene using the N-FINDR method. Subsequently, endmember abundances were estimated for both the image and the sample spectra using fully constrained linear spectral unmixing (FCLSU, [87]). In the classification step, the estimated abundances of the samples and their corresponding class labels were applied to train a RF classifier. For the mineral mapping of the hyperspectral scene, the estimated abundances of the image data were given as input to the trained RF classifier to predict the class label of each pixel in the image. All LWIR image processing is based on reflectance data.

\subsection{Drone-Borne VNIR Hyperspectral Imaging}

For the drone-borne VNIR hyperspectral image acquisition, a Senop Rikola Hyperspectral Imager ([88], Tables 1 and 4) was mounted on an Aibotix Aibot X6v2 hexacopter [89]. The hexacopter platform has a maximum flight time of $15 \mathrm{~min}$ and can be either be controlled manually or operated fully autonomously using a predefined Global Positioning System (GPS) path with automatic start and landing. The UAV-based hyperspectral VNIR dataset was acquired at a $50 \mathrm{~m}$ distance from the target, and from an elevation of about $30 \mathrm{~m}$ above the ground. The imaged scene (consisting of two individual scenes at ca. $2.7 \mathrm{~cm}$ resolution) is a rock face in the center of the outcrop which exposes the plane of a prominent hydrothermal zone (Figure 1D,E).

Table 4. Sensor specifications of the Senop Rikola hyperspectral camera.

\begin{tabular}{cc}
\hline Image size & max. $1010 \times 1010 \mathrm{px}, 50$ spectral bands \\
Field of view (FOV) & $36.5^{\circ} \times 36.5^{\circ}$ \\
Focal length & $\sim 9 \mathrm{~mm}$ \\
Spectral coverage & $500-900 \mathrm{~nm}$ \\
Spectral resolution & $10 \mathrm{~nm}$, full width at half maximum (FWHM) \\
Imaging distance/ground pixel size & $100 \mathrm{~m} / 6.5 \mathrm{~cm}$ \\
\hline
\end{tabular}

Ref. [43] demonstrated that drone-borne hyperspectral imaging requires a specific sequence of pre-processing steps to transform the raw data to meaningful hyperspectral images. A number of Python-based scripts integrated into an in-house toolbox called Mineral Exploration Python Hyperspectral Toolbox (MEPHySTo, [24,43]) and software provided by Senop was used to pre-process the data. The pre-processing steps were as follows (Figure 3):

1. Conversion to radiance: First, a dark current subtraction was performed on the individual images and the raw digital numbers were converted to radiance with the software provided by Senop.

2. Lens correction and co-registration: Specific lens distortions caused by internal camera features were corrected for with the MEPHySTo toolbox. Moreover, spatial shifts between the single bands occurred during image capture, due to sensor movement. Therefore, the spectral bands were co-registered with one another using the toolbox.

3. Orthorectification and georeferencing: Subsequently, the toolbox was used to automatically orthorectify and georeference the images. This was done through keypoint detection and point-matching algorithms to match points between the hyperspectral images and a view-specific pseudo-orthophoto generated from an SfM point cloud.

4. Topographic correction: The topography of the area, such as various orientated slopes, can influence the illumination within an image. The radiance of the same material can vary, due to different sunlight incidences on that material. The MEPHySTo toolbox was used to perform these topographic corrections.

5. Mosaicking: The orthorectified and georeferenced images were then simply merged together using the toolbox, to create a mosaic of the whole area. 
6. Atmospheric correction: Finally, the hyperspectral radiance mosaic was converted to reflectance. An empirical line method was used by using known spectra from black, white, and grey Polyvinyl chloride (PVC) panels placed in the scene.

The UAV-based VNIR image mosaic was masked to exclude parts covered by vegetation and by the reference panels. Subsequently, smoothing was applied using a Savitzky-Golay filter [90]. Image processing of the drone-borne VNIR data is based on SAM using mineral reference spectra and minimum wavelength mapping, but inversely applied to a maximum produced by two flanking minima that may not be well developed, or that may lie outside the spectral range of the sensor.

\subsection{Photogrammetry and $3 D$ Integration}

For photogrammetric surface reconstruction, RGB photographs were acquired from multiple viewpoints on the ground and from unmanned aerial vehicles (UAV). A pre-calibrated Nikon D810 and D850 DSLR camera with a Zeiss Milvus 2/35 ZF.2 lens was used for ground-based imaging, whereas pre-calibrated GoPro Hero 4 Black, Nikon Coolpix A and Canon S110 RGB compact cameras are used for aerial photography (Table 5). For oblique imaging of vertical quarry faces, the Nikon Coolpix A was mounted on a manually-controlled Aibotix Aibot X6v2 hexacopter. Nadir UAV imagery were acquired with the Canon S110 RGB mounted on a Sensefly eBee fixed-wing UAV [91], which was pre-programmed to attain optimal ground resolution, image acquisition time, and image overlap. The eBee has a maximum flight time of $50 \mathrm{~min}$. The orientation of the respective drone and GPS coordinates were written to the EXIF files of individual images in post-flight processing.

Based on the terrestrial as well as UAV nadir and oblique images, the 3D outcrop geometry of the quarry was reconstructed using SfM photogrammetry. SfM is a low-cost, user-friendly workflow combining photogrammetric techniques, 3D computer vision, and conventional surveying techniques. It solves the equations for camera pose and scene geometry automatically using a highly redundant bundle adjustment [50,52]. The typical SfM workflow is performed using Agisoft PhotoScan Professional 1.2.5, following protocols recommended by various authors [57,92]. Processing parameters were set for image alignment to 'high quality' with reference tie point selection. Outlier tie points were removed using the gradual selection tool prior to dense cloud reconstruction at 'high quality', with the depth filtering set to 'aggressive'. Images with high residual tie point errors were excluded from further dense cloud matching. Interior and exterior orientation parameters of the camera were estimated in Agisoft Photoscan based on bundle-block adjustment. The accuracy of the SfM point clouds was validated using a Monte Carlo approach presented by [57], in which the root mean square errors (RMSE) on ground control points (GCP) are calculated based on the actual measured GCP positions and estimated GCP positions in Agisoft PhotoScan. The method uses repeated bundle adjustments, for each of which a random distribution of check and control points is used, and the corresponding RMSE is determined.

During pre-processing, each of the hyperspectral datasets was registered to an SfM point cloud-derived pseudo-orthophoto corresponding to the position and view-direction of the respective hyperspectral sensor using either manual tie points or an automated routine based on keypoint detection and point matching algorithms. By the pixel-wise joining of coordination and spectral information, a so-called "hypercloud" was created, i.e., a geometrically correct, spatially 3-dimensional representation of the hyperspectral data cube or its derivatives (Figure 3). 
Table 5. SfM parameters for the point clouds of the Naundorf quarry.

\begin{tabular}{|c|c|c|c|}
\hline SfM Dataset & 11 May 2011 & 19 October 2017 & 04 April 2018 \\
\hline Aligned images & 186 & 239 & 214 \\
\hline Image acquisition & $\begin{array}{c}\text { UAV-based: DJI Phantom } 2 \text { (GoPro Hero } 4 \text { Black, } \\
12 \text { MP), eBee (Canon Powershot } 110 \text { HS, } 16 \mathrm{MP}) \\
\text { ground-based: Nikon D810 + Zeiss Milvus } \\
\text { 2/35 ZF.2 (36 MP) }\end{array}$ & $\begin{array}{l}\text { UAV-based: Aibot (Nikon } \\
\text { Coolpix A, } 16 \mathrm{MP})\end{array}$ & $\begin{array}{l}\text { UAV-based: Aibot (Nikon } \\
\text { Coolpix A, } 16 \mathrm{MP}), \text { eBee (Canon } \\
\text { Powershot 110 HS, } 16 \mathrm{MP} \text { ) } \\
\text { ground-based: Nikon D850 + } \\
\text { Zeiss Milvus 2/35 ZF.2 (45 MP) }\end{array}$ \\
\hline Average flying altitude (m) & 89 & 43 & 86 \\
\hline Ground resolution (cm/pix) & 2.45 & 1.11 & 1.61 \\
\hline $\begin{array}{l}\text { Ground control point } \\
(\mathrm{GCP}) \text { number }\end{array}$ & $\begin{array}{l}\text { directly georeferenced with eBee onboard GPS } \\
\text { data, subsequently aligned with } 19 \text { Oct. } 2017\end{array}$ & 15 & 25 \\
\hline GCP measurement & - & $\begin{array}{l}\text { Trimble R4-2 PPK GNSS + } \\
\text { Trimble M3 Total Station }\end{array}$ & $\begin{array}{l}\text { Trimble R10 RTK GNSS + } \\
\text { Trimble M3 Total Station }\end{array}$ \\
\hline $\begin{array}{c}\text { Root mean square (RMS) } \\
\text { projection error tie points (pix) }\end{array}$ & 1.59 & 0.48 & 0.16 \\
\hline Control points RMSE $(\mathrm{cm})$ & - & 86.86 & 3.24 \\
\hline Check points RMSE (cm) & - & 106.85 & 3.70 \\
\hline Total error $(\mathrm{cm})$ & - & 89.53 & 3.41 \\
\hline Total error $(X, Y, Z$ in $\mathrm{cm})$ & - & $80.44,80.44,39.29$ & $1.84,1.23,2.59$ \\
\hline
\end{tabular}

\subsection{XRD and Spectrometric Analysis}

Standard petrographic thin sections were prepared from the hand samples, and examined using a Zeiss Axio Imager Z2M microscope using plane- and cross-polarized light, as well as reflected light. For XRD analysis, the samples were manually ground to $<400 \mu \mathrm{m}$ and further micronized to approximately $4 \mu \mathrm{m}$ using a McCrone mill (Retsch). They were filled into the samples holder using the backloading technique. XRD analysis was carried out using a PANalytical Empyrean diffractometer, which was equipped with a Co-tube, Fe-Filter, and a PIXcel 3Dmedipix area detector. The irradiated area was kept constant at $12 \times 12 \mathrm{~mm}$ by means of an automated divergence slit. Data were collected in a 2theta range of $5-80^{\circ}$. Quantitative data were obtained (Table 6) using the Rietveld method and applying the software package BGMN/Profex v. 3.9.2 [93]. Additionally, oriented samples on glass substrates were prepared in order to specify the clay minerals in the samples, where necessary.

Laboratory spectral measurements of both altered and fresh rock surfaces, as well as sample powders, were acquired using a Spectral Evolution PSR-3500 portable spectro-radiometer. Spectra were recorded for the VNIR/SWIR part of the electromagnetic spectrum (400 to $2500 \mathrm{~nm}$ ) with a spectral resolution of $3.5 \mathrm{~nm}(1.5 \mathrm{~nm}$ sampling interval) in VNIR, and $7 \mathrm{~nm}(2.5 \mathrm{~nm}$ sampling interval) in the SWIR using a contact probe ( $8 \mathrm{~mm}$ spot size) with an internal light source. Radiance values were converted to reflectance using a calibrated Zenith polymer polytetrafluoroethylene (PTFE) target with $>99 \%$ reflectance in VNIR and $>95 \%$ reflectance in SWIR, which was measured at regular intervals. Each spectral record consists of 10 individual measurements taken consecutively and averaged.

MWIR to LWIR spectral measurements were obtained using an Agilent 4300 Fourier Transform Infrared (FTIR) spectrometer (Agilent, Santa Clara, United States) with a DRIFT sensor. The spectral resolution was set to $8 \mathrm{~cm}^{-1}$ and the spectral range limited to $1430-830 \mathrm{~cm}^{-1}$ (ca. 7-12 $\mu \mathrm{m}$ ) to match the resolution and spectral range of the Telops Hyper-Cam LW data. Radiance values were converted to reflectance using a pre-calibrated SpectraGold target with $>95 \%$ reflectance. Each spectral record consists of 32 individual measurements taken consecutively and averaged.

\section{Results: Case Study Naundorf Quarry (Germany)}

\subsection{Validation Data}

The host rocks of the Naundorf quarry consist of medium to coarse-grained, porphyritic monzogranites containing mafic magmatic enclaves of quartz monzonitic composition. The enclaves exhibit an irregular shape and are up to $30 \mathrm{~cm}$ in diameter. Locally, the intrusive assemblage is cut by up to $10 \mathrm{~cm}$ wide, microgranitic aplite dykes (Figure 2A). The monzogranites are mainly composed of 
plagioclase, quartz, K-feldspars, chlorite, and biotite (Figure 4A, Table 6). The monzogranite contains euhedral plagioclase crystals up to $3 \mathrm{~mm}$ in size, exhibiting magmatic zonation. Quartz xenocrysts are rimmed by biotite (ocellar texture), suggesting magma mixing between mafic and felsic melts (e.g., $[94,95])$, which is consistent with published interpretations based on geochemical data from the Niederbobritzsch Granite [96,97]. The quartz monzonitic enclaves exhibit the same porphyritic texture, but have a finer-grained matrix (Figure 4B) and contain less quartz than the felsic host and additional amphibole (ferro-pargasite, see Table 6). Compositionally, the microgranite is almost identical to the monzogranite (Table 6), but it displays an equigranular texture (Figure 4C). Hydrothermal zones contain disseminated sulfides, and are characterized by silicification, brecciation, sericitisation, and carbonate precipitation (Figure $3 \mathrm{~B}$ ). In the hydrothermal zones, feldspars and biotite in the monzogranitic host rock are partly (Figure 4D) to completely (Figure 4E) replaced by chlorite and sericite. Quartz occurs in interstices and as strain fringes adjacent to pyrite (Figure 4D). Locally, massive, up to $8 \mathrm{~cm}$ wide sphalerite- and pyrite-bearing quartz veins are encountered in the center of certain larger (NNE-SSW striking) hydrothermal zones (Figure 4F). A rock face in the center of the outcrop, which is the target of the drone-borne VNIR imaging and also part of the ground-based VNIR-SWIR scene (Figure 1E), exposes the plane of a prominent hydrothermal zone $(125 / 58=$ dip azimuth/dip). The exposed fault plane is stained yellowish-brown by the occurrence of sulfides (mainly pyrite) and a suite of secondary alteration minerals.
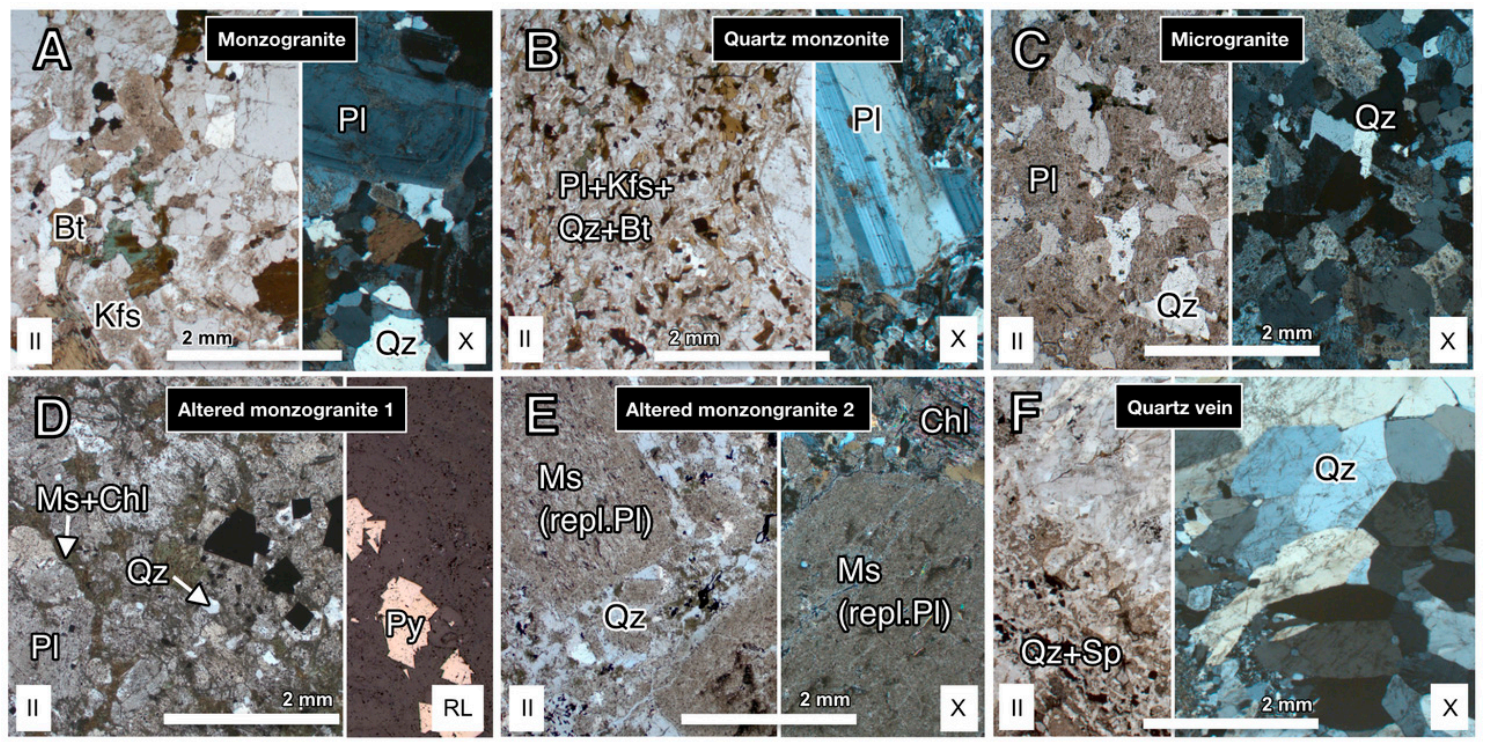

Figure 4. Photomicrographs of representative samples from the NW part of the Naundorf quarry. (A) Monzogranite; (B) Quartz monzogranite; (C) Microgranite; (D) Altered monzogranite 1; (E) Altered monzogranite 2; (F) Quartz vein. Abbreviations are as follows: II—plane polarized light, $\mathrm{X}$ —cross-polarized light, RL—reflected light. Mineral abbreviations after [98].

\subsection{Ground-Based VNIR-SWIR Hyperspectral Imaging}

For the terrestrial VNIR-SWIR hyperspectral dataset of the Naundorf quarry, minimum wavelength maps were generated in four diagnostic wavelength ranges as a means to identify domains of contrasting mineralogy (Figure 5A-D). For validation, the frequency distribution of minimum wavelengths in these respective MWL maps were compared with (i) wavelengths of prominent absorption features in the VNIR-SWIR sample spectra (Figure 6A-F), which were automatically extracted using a filter width of $30 \mathrm{~nm}$, and (ii) absorption wavelengths of infrared-active minerals identified in XRD and in outcrops (Figure 6G,H). Absorption features for fresh and altered parts of the samples were plotted separately to allow for the differentiation of constituents of the fresh or bulk rock and secondary minerals on the rock surface. 
Table 6. X-ray diffraction results for samples from the NW part of the Naundorf quarry. Mineral abbreviations after [98].

\begin{tabular}{|c|c|c|c|c|c|c|c|c|c|c|c|}
\hline \multicolumn{6}{|c|}{ Host Rock } & \multicolumn{6}{|c|}{ Hydrothermal Zone } \\
\hline \multicolumn{2}{|c|}{ Monzogranite } & \multicolumn{2}{|c|}{ Quartz Monzonite } & \multicolumn{2}{|c|}{ Microgranite } & \multicolumn{2}{|c|}{ Altered Monzogranite 1} & \multicolumn{2}{|c|}{ Altered Monzogranite 2} & \multicolumn{2}{|c|}{ Quartz Vein } \\
\hline Phase & wt. $\% \pm 3 \sigma$ & Phase & wt. $\% \pm 3 \sigma$ & Phase & wt. $\% \pm 3 \sigma$ & Phase & wt. $\% \pm 3 \sigma$ & Phase & wt. $\% \pm 3 \sigma$ & Phase & wt. $\% \pm 3 \sigma$ \\
\hline $\mathrm{Pl}\left(\mathrm{An}_{10-50}\right)$ & $38.2 \pm 0.3$ & $\mathrm{Pl}\left(\mathrm{An}_{10-50}\right)$ & $39.2 \pm 0.4$ & $\operatorname{Pl}\left(\mathrm{An}_{0-16}\right)$ & $34.1 \pm 0.8$ & $\operatorname{Pl}\left(\mathrm{An}_{0-10}\right)$ & $38.4 \pm 1.0$ & Qz & $60^{1}$ & Qz & $91.2 \pm 0.5$ \\
\hline $\mathrm{Qz}$ & $29.3 \pm 0.1$ & $\mathrm{Kfs}$ & $22.2 \pm 0.2$ & $\mathrm{Qz}$ & $29.8 \pm 0.6$ & $\mathrm{Qz}$ & $31.6 \pm 0.8$ & $\hat{\mathrm{Ms}}$ & $32^{1}$ & $\widehat{\mathrm{Cal}}$ & $6.9 \pm 0.5$ \\
\hline $\mathrm{Kfs}$ & $20.3 \pm 0.2$ & Qz & $12.6 \pm 0.1$ & $\mathrm{Kfs}$ & $21.9 \pm 0.8$ & Ms & $12.7 \pm 0.7$ & Kln & $8^{1}$ & Py & $1.6 \pm 0.2$ \\
\hline Chl & $8.0 \pm 0.2$ & Chl & $10.1 \pm 0.3$ & Chl & $6.6 \pm 0.8$ & Chl & $9.5 \pm 0.9$ & & & $\mathrm{Sp}(\mathrm{Fe})$ & $0.3 \pm 0.2$ \\
\hline \multirow[t]{4}{*}{$\mathrm{Bt}$} & $4.2 \pm 0.1$ & Ilt & $5.3 \pm 0.1$ & $\mathrm{Bt}$ & $5.0 \pm 0.4$ & Py & $3.9 \pm 0.3$ & & & & \\
\hline & & $\mathrm{Bt}$ & $4.9 \pm 0.1$ & Cal & $2.6 \pm 0.4$ & Cal & $3.5 \pm 0.5$ & & & & \\
\hline & & Fprg & $4.6 \pm 0.1$ & & & $\mathrm{Sp}(\mathrm{Fe})$ & $0.4 \pm 0.1$ & & & & \\
\hline & & Ap & $1.0 \pm 0.0$ & & & & & & & & \\
\hline
\end{tabular}

${ }^{1}$ semi-quantitative, as no appropriate structure model for the Rietveld refinement could be found for this sample. 
In the Al-OH range (2160-2220 nm), the wavelengths of the most pronounced reflection minimum in the VNIR-SWIR image range between 2190 and $2203 \mathrm{~nm}$ in a left-skewed distribution (Figures 5A and $6 \mathrm{H}$ ). The absorption band centered around $2200 \mathrm{~nm}$ is diagnostic of white mica, and the minimum wavelength of this feature is mostly controlled by the octahedral $\mathrm{Al}$ content and the ratio of $\mathrm{K}$ and $\mathrm{Na}[18,99,100]$, which may change due to fluid-rock interactions. As the octahedral Al content and the extent to which $\mathrm{K}$ is replaced by $\mathrm{Na}$ is strongly influenced by $\mathrm{pH}$, temperature, and pressure of the hydrothermal fluid, the $2200 \mathrm{~nm}$ feature is a sensitive indicator for hydrothermal alteration and associated mineralization (e.g., [61]). In the corresponding minimum wavelength map (Figure 5A), a series of vertical linear features (and a rectangular area corresponding to the exposed fault surface in the center of the scene) in bright green and a cyan-colored patch in the upper left part of the scene, indicating intermediate wavelengths of around 2196-2199 nm, distinctively stand out from a background of deep green, brown, and blue, i.e., low-depth features with wavelengths over the entire mapped wavelength range. This pattern suggests a trend of the $2200 \mathrm{~nm}$ feature from lower wavelengths (i.e., a more phengitic composition) and higher wavelengths (i.e., a more paragonitic composition) towards intermediate, i.e., normal sericitic compositions in the hydrothermally altered zones. This trend is also apparent in sample spectra as one goes from samples of host-rocks and slightly altered rocks to "altered monzogranite 2 ", the most pervasively altered rock type (see also Table 6). The depth of the $2200 \mathrm{~nm}$ feature, on the other hand, and its relation to the depth of the $\mathrm{OH}-\mathrm{H}_{2} \mathrm{O}$ feature around $1900 \mathrm{~nm}$ is related to the crystallinity of the mica (e.g., [73,101]); zones of lower mica crystallinity typically being associated with higher amounts of water in the crystal structure, and vice versa. In the Naundorf scene, a band ratio of the $\mathrm{Al}-\mathrm{OH}$ feature at $2202 \mathrm{~nm}$ and the water feature in this dataset anomalously occurring at $1943 \mathrm{~nm}$, indicating the presence of flourine-rich mica or other phases in the Naundorf rocks (e.g., [102,103]), was used as a proxy for the mica crystallinity (Figure 5B). In this image, values of higher mica crystallinity are spatially associated with hydrothermal zones. This may be related to plagioclase breakdown and formation of authigenic white mica, which is often observed in zones of hydrothermal alteration (e.g., [104]), and are evident in the thin sections and XRD results of the Naundorf rocks.

In the $\mathrm{Fe}-\mathrm{OH}$ range between 2250 and $2264 \mathrm{~nm}$, the minimum wavelength distribution within the VNIR-SWIR image is bimodal (Figure 6H). In the corresponding MWL map (Figure 5C), the first distribution peak centered around $2252 \mathrm{~nm}$ is represented by yellow to orange patches in the center of the outcrop that most likely corresponds to zones with relatively high abundances of intermediate chlorite. However, the maximum mapped feature depth is only $3 \%$, which is consistent with the low amount of chlorite detected in the rock samples (only up to $10 \mathrm{wt} . \%$, Table 6). The smaller peak in the minimum wavelength frequency distribution (Figure $6 \mathrm{H}$ ) corresponds to dark blue areas in the periphery of the outcrop and along hydrothermal zones, suggesting these zones have low chlorite abundances with lower $\mathrm{Mg} / \mathrm{Fe}$ composition. This agrees with the lack of evidence for chlorite in the spectral and XRD analyses for samples in the cores of hydrothermal zones ("altered monzogranite 2" and "quartz vein"). Biotite also has key absorption features within the mapped wavelength range, but biotite was unlikely to be detected in the spectra due to low abundances in the rocks (up to $5 \mathrm{wt} . \%$, Table 6) and low reflectivity in the SWIR (e.g., [19]).

Absorption features between 2310 and $2350 \mathrm{~nm}$ are caused by $\mathrm{Mg}-\mathrm{OH}$ and $\mathrm{CO}_{3}$ bond stretching [13], and thus, alteration minerals such as actinolite, chlorite, biotite, epidote and carbonates exhibit characteristic absorption features within this range. The MWL image for the wavelength range between 2335 and $2352 \mathrm{~nm}$ shows a bimodal distribution, with one of the peaks centered around $2339 \mathrm{~nm}$, and the other around $2348 \mathrm{~nm}$ (Figure 5D). The first peak is attributed to carbonates such as calcite and/or siderite based on field evidence, known sample composition, and the color variations in the MWL map, showing olive-brown areas (=low carbonate), and distinct yellow patches and streaks in areas of mapped hydrothermal zones (=high carbonate). Minimum wavelengths around $2348 \mathrm{~nm}$ exhibits only low color intensity, i.e., have low depth, and they may correspond to variations in white mica and chlorite abundances and composition. 

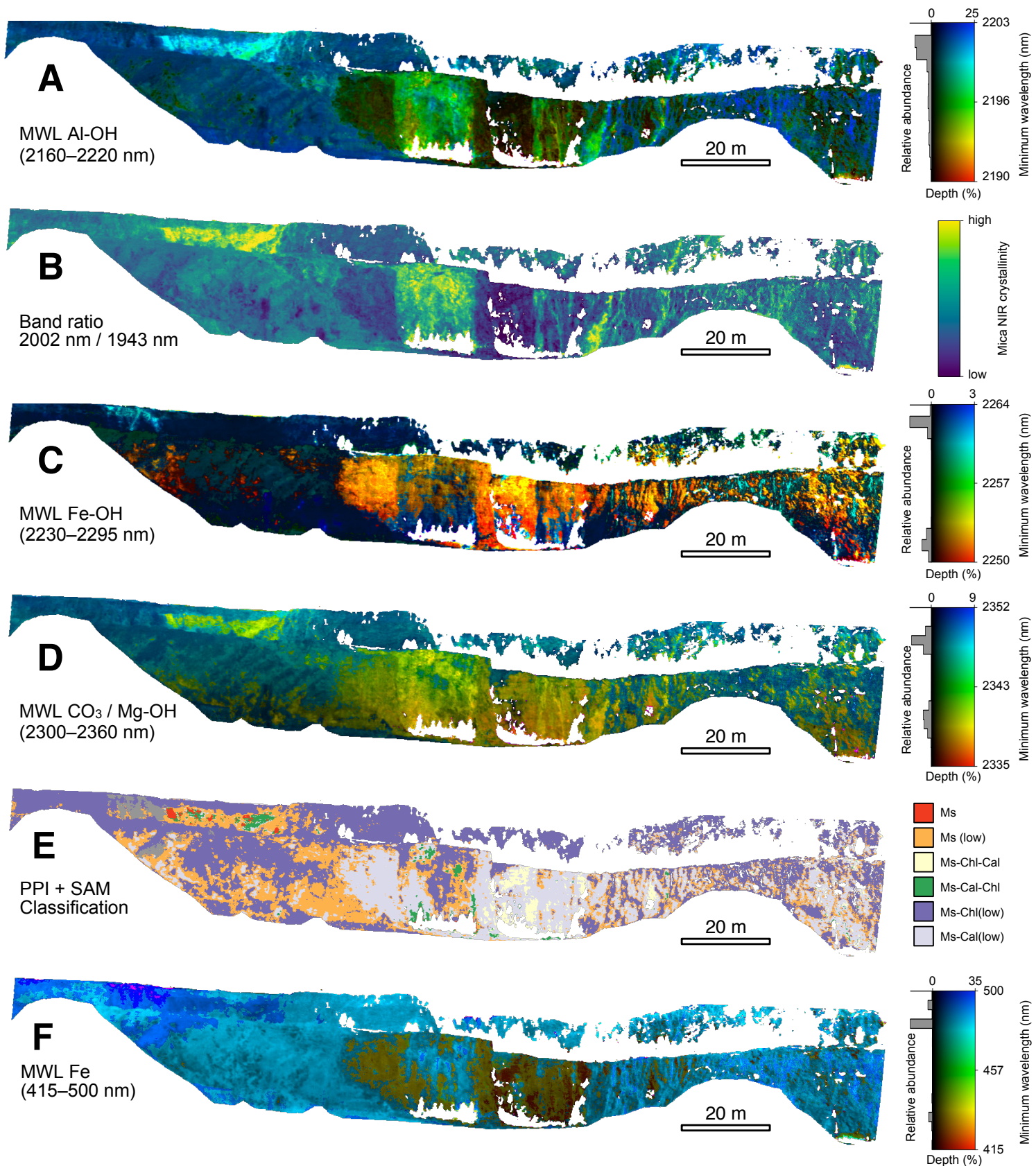

Figure 5. Image processing results for the terrestrial VNIR-SWIR hyperspectral data. (A) Minimum wavelength (MWL) map for wavelength range characteristic for $\mathrm{Al}-\mathrm{OH}$-bearing alteration minerals. (B) Band ratio of the $\mathrm{Al}-\mathrm{OH}$ band at $2202 \mathrm{~nm}$ and the $\mathrm{H}_{2} \mathrm{O}$ band at $1943 \mathrm{~nm}$ as a measure of mica crystallinity. (C) MWL map for the Fe-OH range. (D) MWL map for $\mathrm{Mg}-\mathrm{OH} / \mathrm{CO}_{3}$-bearing alteration minerals. (E) Classification map derived by pixel purity index (PPI) endmember extraction, visual endmember spectral analysis, and spectral angle mapping (SAM). Classes correspond to lithological zones, where minerals or mineral groups that are identifiable in the VNIR-SWIR range are dominant. "Low" refers to spectral signatures with low depths. Mineral abbreviations after [98]. (F) MWL map for the VNIR range to discriminate between iron-bearing alteration minerals. See Figure $6 \mathrm{G}, \mathrm{H}$ for the location of absorption maxima in the VNIR and SWIR range, respectively. 

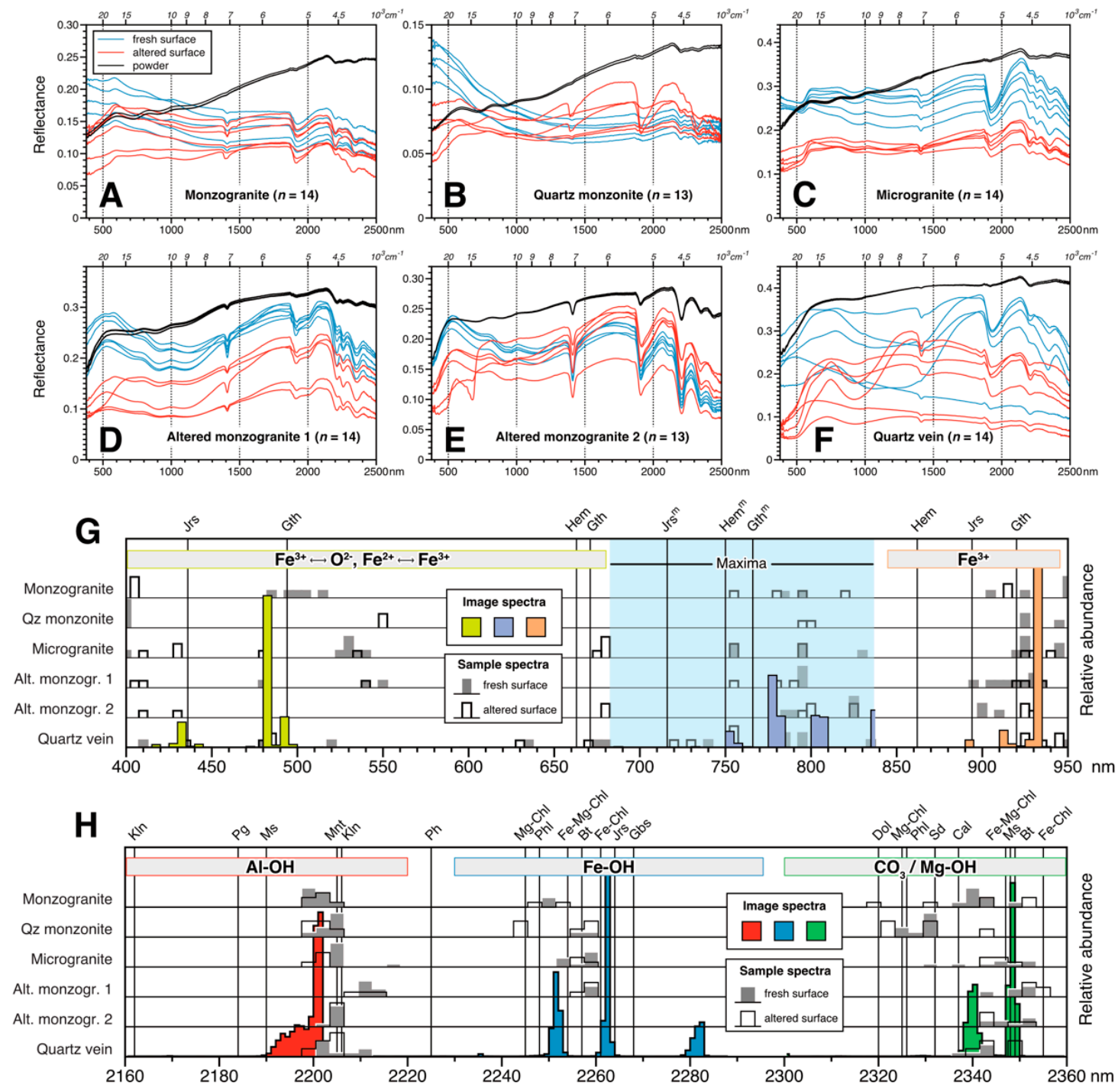

Figure 6. (A-F) VNIR-SWIR spectra for samples from the Naundorf quarry recorded with a Spectral Evolution handheld spectrometer. Powder spectra were offset to lower the reflectance values for clarity. (G) Diagram showing absorption features in the VNIR range for (i) selected iron alteration minerals (black vertical lines, positions for reflectance minima and maxima from [74], mineral abbreviations after [98]), (ii) sample spectra (grey and white histograms, $5 \mathrm{~nm}$ bin width), and (iii) image pixels (color-filled histograms, $5 \mathrm{~nm}$ bin width) within the continuum-removed wavelength ranges $400-680 \mathrm{~nm}$ and $845-945 \mathrm{~nm}$. Maxima within the range of $682-838 \mathrm{~nm}$ are extracted from non-continuum-removed spectra. (H) Diagram analogous to $(\mathbf{G})$ for the upper SWIR range (1 nm bin width). Absorption wavelength positions of selected alteration minerals from [19,73]. Abbreviations:

"Alt."-altered, "monzogr."-monzogranite.

The information gained from the minimum wavelength maps was confirmed and refined with a classification of the VNIR-SWIR image (Figure 5E). The classification is based on the visual inspection of seven spectral endmembers extracted using PPI and n-Dimensional visualizer in the ENVI software. This manual approach considers not only the position of absorption maxima in the upper SWIR range, but also the positions and shapes of all absorption features over the entire spectral range of the sensor (save for two bands of strong atmospheric absorption). The main identified minerals are white micas generalized as muscovite, followed by chlorite and calcite. Muscovite was identified based on its specific $\mathrm{Al}-\mathrm{OH}$ feature in correlation with the $\mathrm{OH}-\mathrm{H}_{2} \mathrm{O}$ feature at ca. $1940 \mathrm{~nm}$. Chlorites show an intermediate $\mathrm{Mg}-\mathrm{Fe}$ composition based on the main diagnostic Fe-OH-Mg-OH feature located between 2250 and $2260 \mathrm{~nm}$. 
Calcite was identified based on the specific carbonate feature present between 2336 and $2340 \mathrm{~nm}$ [73]. Due to the overlap with chlorite and muscovite features in this range, the depth of this feature in relation to the other diagnostic absorptions of muscovite and chlorite was considered for the documentation of calcite. The vertical features in the classification map composed of the classes "Ms", "Ms(low)", "Ms-Cal(low)", and "Ms-Cal-Chl" correspond to the hydrothermal zones identified in the field, whereas the majority of granitoid host rocks were mapped as "Ms-Chl(low)" and "Ms-Chl-Cal".

MWL maps for the wavelength ranges between 845 and $945 \mathrm{~nm}$, as well as 400 and $680 \mathrm{~nm}$, were generated to identify and map supergene iron minerals that, because of their low volumetric abundance, may have gone unnoticed in the XRD analyses and may be masked by other phases (e.g., clay minerals) in the SWIR part of the spectrum. Although scarce, iron minerals do occur in the featured outcrop, as indicated by the presence of diagnostic absorptions in the spectral range from 0.4 to ca. $1.2 \mu \mathrm{m}$ related to intervalence charge transfers (for instance, between $\mathrm{Fe}^{3+}$ and $\mathrm{O}^{2-}$, or between $\mathrm{Fe}^{3+}$ and $\mathrm{Fe}^{2+}$ ) and crystal field transitions (e.g., [74,105-108]) in image and sample spectra (Figures 5F and 6G). Absorptions features between 845 and $945 \mathrm{~nm}$ are observed at $292 \mathrm{~nm}, \sim 912 \mathrm{~nm}$ and $930 \mathrm{~nm}$ in the image, and between 910 and 930 in spectra from sample surfaces (Figure 6G), which indicates the presence of goethite and jarosite, but excludes hematite as an occurring phase, because the position of the reflectance minimum for the hematite group is near $860 \mathrm{~nm}$. However, goethite and jarosite cannot be clearly differentiated in this wavelength range, as both minerals have broad absorptions near $900 \mathrm{~nm}$ (e.g., goethite 910-940 nm, jarosite: 900-925 nm, [108]). In the range from 400 to $680 \mathrm{~nm}$, on the other hand, goethite has additional features near 480-500 nm and at $670 \mathrm{~nm}$, and jarosite exhibits an absorption band at $437 \mathrm{~nm}$ (e.g., [74]). In the corresponding MWL map (Figure 5E), goethite, identified by pixels with minimum wavelengths between $\sim 450$ and $\sim 480 \mathrm{~nm}$ (Figure 6G), appears to be ubiquitous over the entire scene, but exhibits low depths in parts identified as host rocks in the field, and greater depths along fault planes in the upper left and center of the VNIR-SWIR image as well as in an area close to the quarry floor in the left part of the scene. The abundance of goethite is also indicated by the majority of image and sample spectra exhibiting reflectance maxima at higher wavelengths than either jarosite and hematite (Figure 6G). Jarosite, on the other hand, corresponding to minima at $\sim 32 \mathrm{~nm}$, preferentially occurs in the center of the outcrop where there is a notable abundance of hydrothermal zones.

\subsection{Ground-Based LWIR Hyperspectral Imaging}

Following the acquisition and pre-processing scheme outlined in the Methods chapter, a LWIR mosaic was created from an array of $3 \times 4$ single scenes with a ground resolution of ca. $2.2 \mathrm{~cm}$ (Figure 7B). Based on XRD results of the samples collected in the field (Table 6), mineralogical endmembers were defined. Corresponding mineral reference spectra from spectral libraries ([19] and Arizona State University Spectral Library) were then mapped using LSU. The resulting albite-quartz-muscovite RGB composite image (Figure 7C) allows a clear distinction between the hydrothermal zone and the surrounding granitoid host. Additionally, the image highlights (i) compositional variabilities in the granitoid host-rocks from more quartz-rich (greenish yellow, i.e., the monzogranite host) to more plagioclase-rich varieties (orange-red, i.e., mafic enclaves), and (ii) different components of the hydrothermal zone, such as pervasively seritized monzogranites (deep blue) and quartz veins (green linear features).

Between 16 and 29 LWIR point spectra were acquired per sample using a handheld FTIR spectrometer to evaluate the spectral variability within a sample (Figure 8). For representative FTIR spectra, either mean or center spectra were used as an input for lithological classifications by SAM (Figure 7D,E). Whereas the mean spectrum represents an "artificial" sample consisting of average reflectance values, the center spectrum constitutes the "physical" sample spectrum closest to the mean. In both classification images, the felsic host rocks are correctly mapped as monzogranites with local occurrences of quartz monzonitic enclaves and varying alteration (corresponding to the mineralogy of altered monzogranite 1). Zones of hydrothermal alteration in the center of the image, as well as in the upper left corner, are delineated by the occurrence of altered monzogranite 2 and vein quartz. 

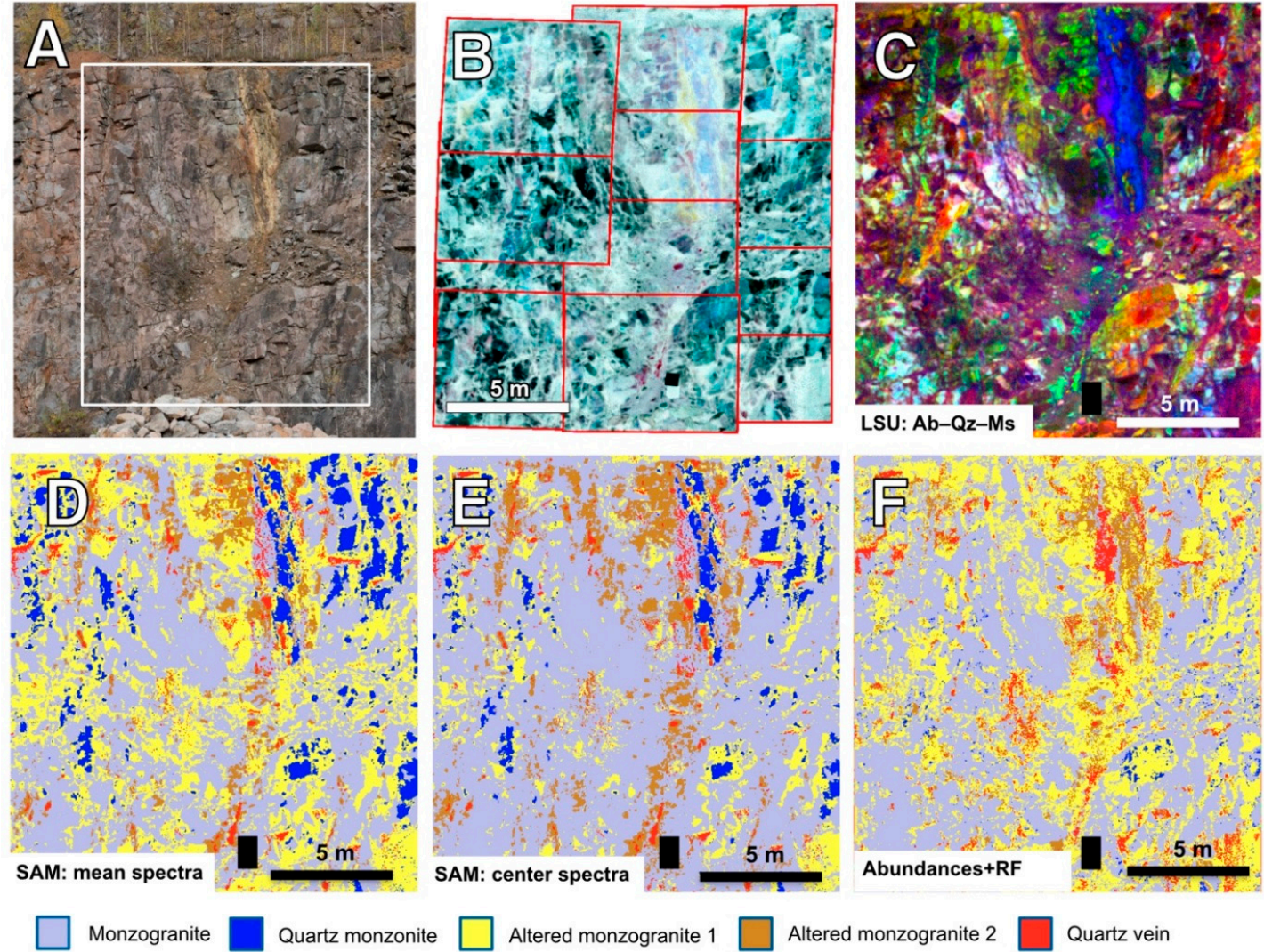

Figure 7. (A) Photograph of the LWIR scene (see Figure 1 for location). (B) Overlap of the 12 LWIR scenes that were mosaicked to a $3 \times 4$ array. (C) Linear spectral unmixing (LSU) results for the LWIR mosaic showing the relative abundance of selected mineral reference spectra [19]. Color stretch 2-98\%. Mineral abbreviations: Ab-albite, Qz-quartz, Ms-muscovite. Black rectangular area at the bottom of the image corresponding to the masked reference panels. (D) Spectral angle map (SAM) based on mean Fourier-transform infrared (FTIR) sample spectra. (E) SAM based on center FTIR sample spectra. (F) Results of a classification approach based on the extraction of endmembers from the scene, unmixing the sample spectra and the scene samples, and using abundance features as an input for a random forest classification.

The third classification result, which is based on a random forest machine learning algorithm (see Methods), uses image and sample spectra as an input, and thus, unlike SAM, considers all the intra-sample heterogeneity. The result correctly maps the distribution of host rocks and hydrothermally altered rocks, but underestimates the abundance of quartz monzonite enclaves (Figure 7F). 

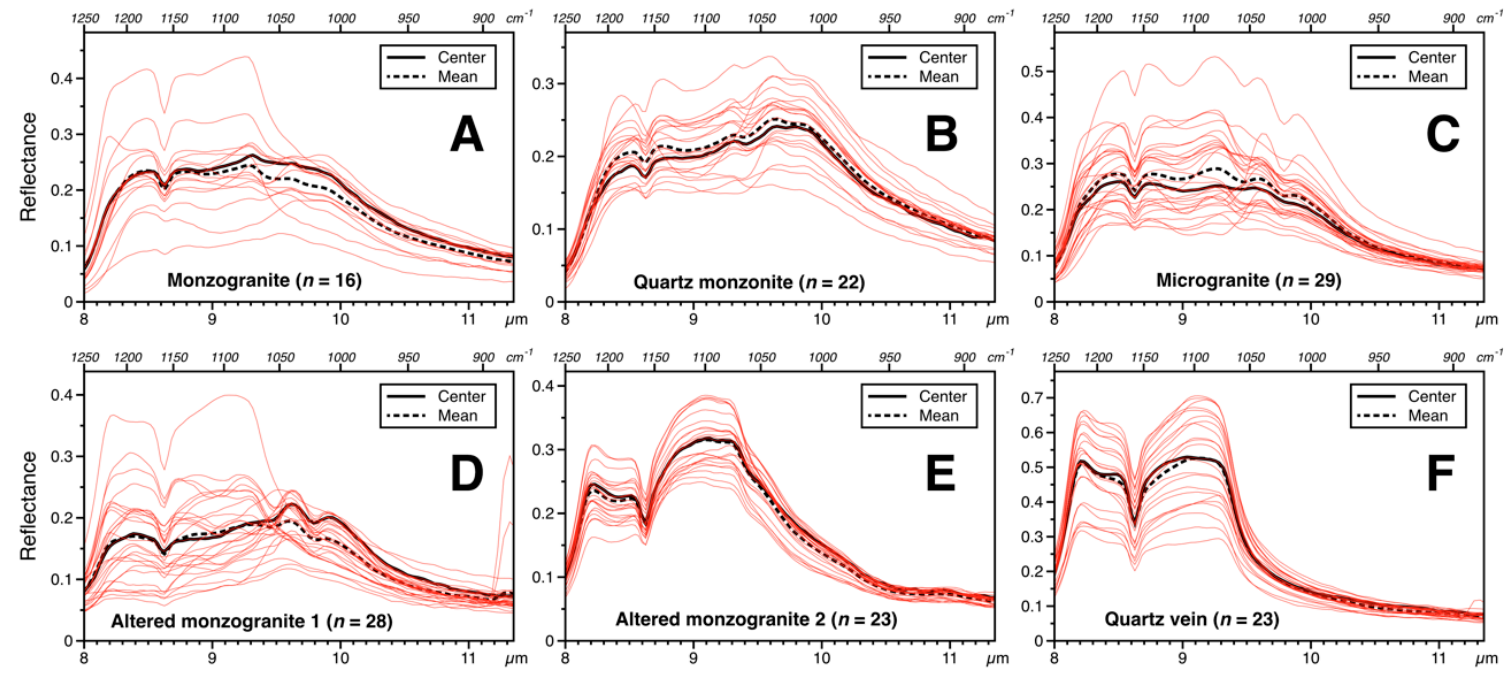

Figure 8. FTIR spectra of samples from the Naundorf quarry. (A) Monzogranite; (B) Quartz monzogranite; (C) Microgranite; (D) Altered monzogranite 1; (E) Altered monzogranite 2; (F) Quartz vein.

\subsection{UAV-Based VNIR Hyperspectral Imaging}

Three samples taken from the accessible lower part of the outcrop (Naun 1-3) targeted by UAV-based VNIR hyperspectral imaging were examined using the Spectral Evolution spectro-radiometer. In the corresponding VNIR-SWIR spectra (Figure 9B), jarosite, goethite, and smectite could be identified based on characteristic absorptions [73,74] at ca. $890 \mathrm{~nm}$ (jarosite) and $912 \mathrm{~nm}$ (goethite) as well as 1411, $\sim 1904$, and 2205-2212 nm (smectite). Reference library spectra [19,74] of minerals identified by spectral analysis were used as input for a SAM classification (Figure 9C), yielding a distribution map with smectite-goethite-jarosite in the order of decreasing abundance. The shape and positions of mean spectra of all classified pixels for each mineral correspond well to the respective sample spectra (Figure 9B). The reflectance maximum occurring between ca. 700 and $770 \mathrm{~nm}$ (e.g., for goethite at $\sim 764 \mathrm{~nm}$ caused by a shoulder near $650 \mathrm{~nm}$, and a broad absorption band near $910 \mathrm{~nm}$; [74,105]), is interpreted as a reliable indicator of the dominant ferric iron-bearing mineral present. This forms the basis for a maximum wavelength mapping (Figure 9D), which shows a similar distribution for the occurrence of goethite or jarosite as the SAM classification, and largely agrees with the spatial distribution of these iron minerals in the corresponding part of the VNIR-SWIR image (Figure 5F). 

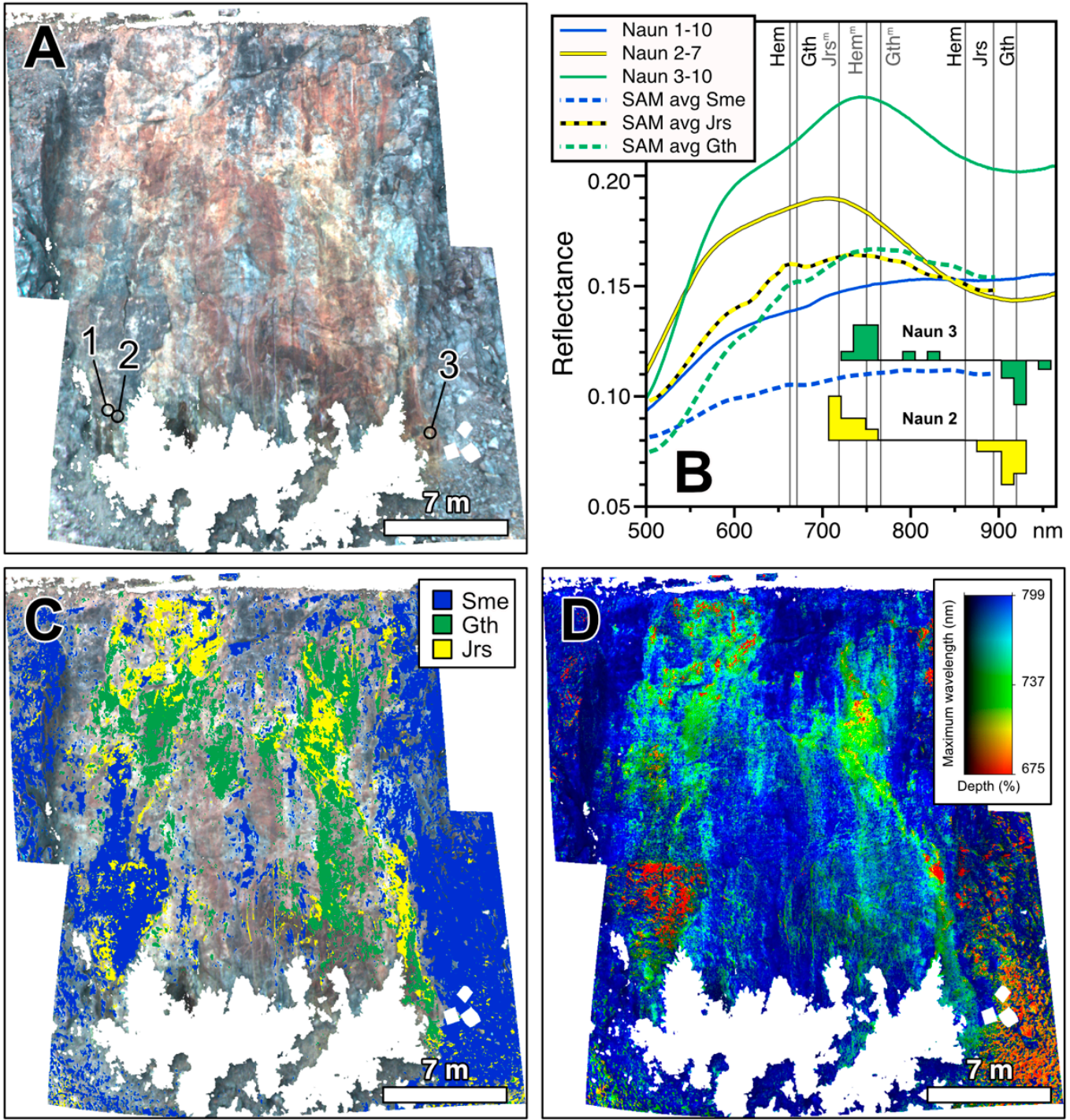

Figure 9. Image processing results of the drone-borne VNIR dataset. (A) RGB mosaic of the acquired scene showing sample locations. Vegetation and calibration panels (bottom right) are masked. (B) VNIR sample spectra recorded with a Spectral Evolution handheld spectrometer (continuous lines), and image spectra (stippled lines) representing the averages of all pixels within the corresponding Spectral Angle Mapper (SAM) class (see Figure 9C). Histograms show the abundance and position of reflectance minima (downward pointing bars) and maxima (upward pointing bars) for the sample spectra $(\mathrm{n}=10$ for each sample). Black vertical lines indicate reflections of the minima and maxima (superscript $\mathrm{m}$ ) of selected supergene secondary iron minerals. Mineral abbreviations after [98]. Naun X-X indicates the sample location (1-3, see Figure 9A) and the number of spectrum (out of 10). The Diagram highlights the likely occurrence of jarosite and goethite in outcrops and in image spectra. (C) SAM results based on reference library spectra (from $[19,74]$ ). Classes correspond to lithological zones, in which the mapped minerals are dominant. (D) "Maximum" wavelength mapping centered on the reflection peak between 675 and $800 \mathrm{~nm}$.

\subsection{SfM Photogrammetry}

SfM photogrammetric models of the Naundorf quarry were produced for topographic correction and fusion with hyperspectral imagery. A crucial benefit of our presented integrative workflow is that one photogrammetric model could be used for different imaging datasets obtained from different positions. However, as the different hyperspectral datasets were acquired not at the same 
time, but on three different occasions over the course of a year, a separate SfM model, which reproduces the geometry, lighting conditions, and vegetation of the quarry at the time of image acquisition, was generated for each of the three hyperspectral datasets (Table 5). The presented median root-mean-square error (RMSE) values for check and control points were calculated from 50 bundle adjustments, with 80 percent of the GCP being used as control points, and the remaining 20 percent as independent check points. The final point clouds were processed using all GCP in the area of interest as control data (total error), which amounts to a total error range of ca. $90 \mathrm{~cm}$ to ca. $3.5 \mathrm{~cm}$ for the last two SfM models, respectively. The hyperclouds, which were based on these models, may have a larger error due to errors being introduced during mosaicking and georeferencing (Table 7).

\section{6. $3 D$ Integration}

Fusing one of the obtained image processing results for each of the hyperspectral datasets of the Naundorf quarry with their corresponding SfM point cloud by manual or automatic georeferencing yielded three hyperclouds, i.e., geometrically and spectrally accurate combinations of a SfM point cloud and a hyperspectral data cube. The georeferencing accuracy, evaluated for each hyperspectral image by collecting $10 \mathrm{GCPs}$ per scene, extracting their real-world coordinates from the pseudo-orthophoto and calculating a root mean square error (RMSE) in X, Y, and Z direction, is between 4 and $28 \mathrm{~cm}$ (Table 7). The integrative 3D datasets can be viewed and evaluated under [109] in a browser (Chrome, Firefox, Safari on desktop PCs and mobile devices) online using the WebGL-based Potree viewer [110]. The viewer allows for rendering of the 3D datasets (SfM point cloud, and terrestrial VNIR-SWIR MWL, terrestrial LWIR LSU, UAV-based MWL hyperclouds), as well as measurements of distance, area, and height profiles. The individual datasets should be viewed separately to avoid occlusions of overlapping datasets. As different hyperspectral datasets were referenced to different point clouds, there may be slight mismatches in the hyperclouds relative to the SfM RGB point cloud. This is due to the varying accuracy of each reference point cloud (Table 7), as well as due to physical changes in the quarry as part of mining operations.

Table 7. Georeferencing accuracies. Abbreviations: Terr.-Terrestrial.

\begin{tabular}{cccc}
\hline Dataset & RMSE X [m] & RMSE Y [m] & RMSE Z [m] \\
\hline UAV VNIR & 0.04 & 0.06 & 0.06 \\
Terr. VNIR-SWIR & 0.15 & 0.21 & 0.28 \\
Terr. LWIR & 0.16 & 0.13 & 0.11 \\
\hline
\end{tabular}

\section{Discussion}

\subsection{Quarry Naundorf}

Image processing of the VNIR-SWIR data from the Naundorf quarry is based on minimum wavelength mapping, band ratios, and endmember-based classifications. The MWL maps are evaluated by comparing the absorption features in image and sample spectra with those of (infrared active) minerals identified in the outcrop, and in thin section or XRD analyses (Figure 6G,H and Figure 9B). Despite an apparent shift between the minimum wavelengths of the reference minerals, image spectra, and sample spectra, which may be caused by spectral noise in image-derived spectra and/or different wavelength ranges having been used for continuum removal during extraction of minimum wavelengths [111], two main lithological zones can be distinguished based on this analysis: (1) hydrothermal zones, characterized by white mica of intermediate, sericitic composition with a high mica crystallinity, in addition to calcite, and (2) host-rocks, which contain comparatively low abundances of white mica of variable composition with low crystallinity, and intermediate chlorite. As a result, the hydrothermal zones of the Naundorf quarry can be clearly delineated as sub-vertical linear features, or irregular surfaces if the faults intersect the host rocks at a low angle to the quarry face. The spatial location of these spectrally identified 
hydrothermal zones correspond well to the alteration zones documented in the field. Moreover, they coincide with a negative relief in the corresponding 3D hypercloud.

Apart from the phyllosilicates and carbonates, supergene iron minerals were identified in the Naundorf outcrop by means of both ground- as well as drone-borne hyperspectral imaging (Figures 5F and 9D). These minerals were not identified by means of XRD or thin section analyses. A plausible explanation for this is the fact that the XRD analysis is conducted on parts of the complete volume of hand samples that are more representative of the fresh, unaltered rock, and thus minerals on sample surfaces may be underrepresented or not detected at all. The compositional discrepancy between the sample surface and its "volume" is clearly illustrated by the different absorption wavelengths of spectra acquired from altered and fresh part of the sample (filled vs. unfilled histograms in Figure 6G,H). The origin of goethite and jarosite mapped along the surfaces of hydrothermal alteration and in the in the center of the VNIR-SWIR image, where hydrothermal zones are most abundant, is most likely related to the occurrence of sulfide minerals. Locally, these supergene minerals trace vertical streaks on the fault surfaces (e.g., Figure 9C,D). The streaks may correspond to zones where water has run down the quarry face and has caused preferential chemical weathering of sulfides (e.g., [112]). Goethite occurring in a horizontal domain at the bottom left of the VNIR-SWIR image (Figure 5F), on the other hand, may be caused by wind-blown iron-mineral-laden dust produced during quarry operations.

LWIR spectra, unlike SWIR spectra, do not contain sharp absorption features that allow for easy material identification by visual spectral evaluation or minimum wavelength mapping. Instead, they are characterized by broad reflectivity features that show only subtle asymmetries, bumps, and shifts in extrema, due to compositional variations of the target rocks. However, as shown in the example, LWIR hyperspectral scenes can be evaluated using standard unmixing and classification techniques that were originally developed for SWIR data. Apart from being able to identify differences in the abundance or composition of phyllosilicates and carbonates, the Naundorf LWIR hyperspectral data can be used to discriminate between quartz- and plagioclase-dominated rock types, respectively. Except for the monzogranite and the microgranite, which are texturally different, but compositionally nearly identical, FTIR sample spectra are distinct enough to be used as endmembers in image classification. Thus, mafic enclaves can be distinguished from the felsic granitoid host, and quartz veins can be identified in the core of hydrothermal alteration zones. The abundance and size of the enclaves vary based on the classification approach, but they by and large correspond to observations in the field. The geometry of individual enclaves on the other hand, locally appearing angular in shape, may be affected by distortions occurring as a result of the roughness of the outcrop. This is apparent in the corresponding 3D hypercloud of the hyperspectral LWIR scene.

\subsection{Benefits of the Integrated Workflow}

Absorptions and emissions of materials in the infrared range occur due to different optico-physical phenomena, i.e., (i) electronic processes, including crystal field effects, charge-transfers, conduction bands, and color centers for wavelengths between ca. 0.1 and $3 \mu \mathrm{m}$, (ii) fundamental vibrational processes for wavelengths greater than ca. $6 \mu \mathrm{m}$, and (iii) overtones and combination bands of metal-OH bond stretching and bending, mainly between 1.0 and $2.5 \mu \mathrm{m}[13,113]$. Our multi-sensor approach covers the VNIR $(0.4-0.9 \mu \mathrm{m})$, SWIR $(0.9-2.5 \mu \mathrm{m})$, and LWIR $(7.7-11.8 \mu \mathrm{m})$ range, in which all of these physical processes operate and cause characteristic spectral signatures for a variety of common geologic materials, including iron oxides, iron hydroxides, and iron sulfates (e.g., [74,105]) as well as rare earth elements $[114,115]$ in the VNIR; "alteration minerals", such as phyllosilicates, hydroxylated silicates, sulphates, carbonates, and ammonium minerals in the SWIR (e.g., [13,73]); and rock-forming minerals including silicates (notably tectosilicates like quartz and feldspar), oxides, carbonates, hydroxides, sulfates, and phosphates in the LWIR $[27,33,116]$. The LWIR outcrop sensing is particulary useful in remotely mapping different rocktypes that cannot be distinguished in RGB, such as marbles, quartzites, or different generations of basalts in mafic dyke swarms. Even though many 
ore metals are indistinct in the spectral range of the sensors used in this study, a variety of alteration minerals related to ore mineralization show intense spectral contrast and can be used as mineralization vectors, pathfinders, or proxies (e.g., [73,101,117]), which makes this sensor combination and described workflow a valuable tool in exploration and mining.

The presented integrated workflow is meant to supplement geological fieldwork by providing a qualitative discrimination of domains and lithological/tectonic contacts, so that the geologist can make informed decisions about focussing mapping efforts and designing a suitable sampling strategy. As with every remotely sensed data, validation by the means of ground truthing is crucial for calibration purposes, training of classification algorithms, quality assessment of models, quantification, etc. To a first degree, geological field work will provide qualitative data, such as an inventory of lithologies, alteration and mineralization types, and quantitative data such as structural measurements of faults and contacts. Petrographic and XRD mineralogical analyses, as well as sample spectra, provide a link between mineralogy and spectral reflectance signature. Apart from mineralogical composition, petrographic thin section analysis can yield valuable extra information on the alteration and the sequence of crystallization. Additionally, the combination of multiple datasets in this integrated approach enable extensive opportunities for cross-validation, i.e., (1) between hyperspectral imaging data based on overlapping spectral ranges (i.e., drone-borne VNIR and ground-based VNIR-SWIR) or (2) between hyperspectral imaging data based on the spatial abundance of minerals that are infrared-active in the respective wavelength ranges (such as phyllosilicates producing diagnostic spectra in SWIR and LWIR), (3) between imaging products and 3D point clouds (by means of hyperclouds) to evaluate the shadowed parts of the image that may lead to misclassifications, or to assess the spatial accuracy of mapped lithologies with a morphological expression, e.g., due to preferential weathering, (4) between the (low-resolution) texture of hyperclouds and the high-resolution RGB textures of corresponding SfM models.

The resolution of the presented datasets (VNIR-2.7 cm, VNIR-SWIR-13 cm, LWIR $-2.2 \mathrm{~cm}$ ) can be controlled by adjusting the range of the sensor or (in the case of LWIR imaging using the Telops Hyper-Cam) by replacing the optics with a longer or wider lens. Resolution is only limited by accessibility (how close the terrestrial scanner can be set up), or by how close the drone can be maneuvered to the outcrop (about 10-15 m). For the present example, the drone-borne hyperspectral sensor was used to map an accessible part of the quarry wall to allow in-situ validation and cross-correlation with the terrestrial VNIR-SWIR data. However, with the presented combination of terrestrial and drone-borne sensors, geological outcrops at spatial scales of up to several hundred square meters in the horizontal to vertical orientation can be easily mapped.

In studies that combine hyperspectral imagery with TLS data, both data sets are usually acquired from one position in order to avoid data gaps due to occlusion in one or the other data set. Hence, for each hyperspectral scan, an accompanying outcrop model has to be acquired. In our presented approach, one single ground- and UAV-based SfM 3D model can be used to fuse many hyperspectral datasets acquired from different horizontal and vertical positions, thus allowing for greater flexibility. TLS data, if acquired from a network of scanning positions, which accessibility conditions will not always allow, is generally deemed to be more precise and consistent across the outcrop in comparison to SfM (e.g., $[48,55,56])$. However, SfM is now an established method which, by following acquisition and processing guidelines (e.g., [57]) can yield reproducible and highly precise 3D models. Combined terrestrial and aerial SfM models have greater coverage and are less prone to occlusion than TLS models, due to the additional camera positions and angles. Moreover, SfM instrumentation is cheaper, lighter, more compact, and requires lower power consumption $[55,56]$.

Regarding data processing, we focus on time-efficient routines which require minimum user input. The applied algorithms include both established methods such as N-FINDR endmember extraction, SAM, MWL mapping, and LSU that are implemented in standard image processing and machine-learning workflows to take full advantage of the entire set of validation spectra. Open source software such as the Hyperspectral Python toolbox (HypPy, e.g., [61,74]) and the Mineral Exploration 
Python Hyperspectral Toolbox MEPHySTo [24,43] are used for image pre- and post-processing, as well as data integration. Even larger datasets can be processed efficiently, due to the employment of batch processing routines for e.g., empirical line correction, co-registration, mosaicking, and georeferencing.

3D hyperclouds, which combine the information of the 3D surface geometry with multi-source, multi-scale hyperspectral imaging products, apart from providing an intuitive visualization, can be used to identify and extract geologic structures, as well as map areal distributions of geologic domains that may be indistinguishable in the visible part of the electromagnetic spectrum. The approach is particularly useful if detailed structural mapping is not possible, due to steepness, size, or safety concerns limiting access to the outcrop. For example, the compass plugin by [118] for the CloudCompare Software (CloudCompare version $2.9,2018$ ) can be used to easily trace lineaments (i.e., least-cost paths) along RGB values and gradients in hyperclouds of suitable spectral contrast. Furthermore, as shown in our example, the 3D hypercloud environment allows for hyperspectral datasets of differing spatial resolution or that are obtained with different acquisition parameters, to be set into spatial relation. Within this framework, hyperspectral surface information (i.e., 2.5D) can be combined with subsurface data such as drill-cores to build fully $3 \mathrm{D}$ structural and mineral resource models.

\section{Conclusions}

The presented workflow for the combination of structure-from-motion (SfM) outcrop models and multi-sensor hyperspectral imagery acquired from terrestrial and airborne platforms provides an important source of geological information for geoscientific research, mineral exploration, mining, and geohazard monitoring, with many advantages over traditional approaches with respect to:

1. spectral range, as the combination of visible to near infrared, shortwave infrared, and long-wave infrared hyperspectral imaging enables the discrimination of a variety of geologic materials such as rock-forming and hydrothermal alteration minerals;

2. spatial coverage, as the combined use of ground-based sensors and unmanned aerial vehicles (UAV) allows for close-range imagery with higher spatial resolutions to be acquired of geological outcrops from a number of perspectives;

3. flexibility, as SfM outcrop models based on terrestrial and aerial photographs are less influenced by occlusion, and can serve as a basis for fusion of multiple spectral datasets with different sensor positions;

4. validation, as geological field observations and analytical validation data are supplemented by a range of cross-validation data between the individual datasets of the multi-sensor approach;

5. cost- and time-efficiency, as the SfM approach offers a fast and low-cost alternative to terrestrial laser scanning and the presented hyperspectral processing routine, which is mostly based on open source code, requires only minimal user input;

6. geological interpretation, as the hypercloud, i.e., a geometrically correct, spatially 3-dimensional representation of the hyperspectral data cube or its derivatives, allows for an intuitive visualization of geological outcrops, and it can be used to identify and extract geologic structures as well as map areal distributions of lithologic domains.

The benefits gained from the presented integrated approach will be amplified by current developments in (i) sensor development hyperspectral technology, resulting in the availability of small and lightweight imaging sensors with extended wavelength ranges (e.g., [119]), (ii) machine-learning algorithms to improve classifications based on the fusion of topographic and spectral data (e.g., [120,121], (iii) the augmentation of topographic and spectral surface data with subsurface information from drill-cores and/or geophysical data to build fully 3D structural and mineral resource models (e.g., [122]), and (iv) algorithms and hardware to allow for real-time processing of photogrammetric data and hyperspectral images (e.g., [123]). 
Author Contributions: Conceptualization, M.K. and R.G.; Methodology, M.K., S.L., R.M.; Software, S.L., M.K.; Formal Analysis, M.K., S.L., L.T., M.K., P.H., R.Z.; Investigation, M.K., R.Z., S.L., L.T., P.H..; Writing-Original Draft Preparation, all authors; Writing-Review \& Editing, all authors; Visualization, M.K., S.L.; Supervision, R.G., M.K.; Project Administration, R.G., M.K.

Funding: This research received no external funding.

Acknowledgments: The Helmholtz Institute Freiberg for Resource Technology is gratefully thanked for supporting and funding this project. Naundorfer Naturstein $\mathrm{GmbH}$ \& Co KG is acknowledged for access to the quarry Naundorf. M.K. is grateful to Andreas Kaiser (Geocoptix GmbH) and Anette Eltner (TU Dresden) for their discussions and help with method development. Special thanks go to Benjamin Melzer, Doreen Ebert, and Stefan Richter for sample preparation. Reviews by Isabel Cecilia Contreras Acosta and Robert Jackisch improved the text. We also thank Assistant Editor Ansley Li for handling of the manuscript and three anonymous reviewers for constructive comments.

Conflicts of Interest: The authors declare no conflict of interest.

\section{References}

1. Hodgetts, D.; Drinkwater, N.J.; Hodgson, J.; Kavanagh, J.; Flint, S.S.; Keogh, K.J.; Howell, J.A. Three-dimensional geological models from outcrop data using digital data collection techniques: An example from the Tanqua Karoo depocentre, South Africa. GSL Spec. Pub. 2004, 239, 57-75. [CrossRef]

2. Enge, H.D.; Buckley, S.J.; Rotevatn, A.; Howell, J.A. From outcrop to reservoir simulation model: Workflow and procedures. Geosphere 2007, 3, 469-490. [CrossRef]

3. Rotevatn, A.; Buckley, S.J.; Howell, J.A.; Fossen, H. Overlapping faults and their effect on fluid flow in different reservoir types: A LIDAR-based outcrop modeling and flow simulation study. AAPG Bull. 2009, 93, 407-427. [CrossRef]

4. Buckley, S.J.; Enge, H.D.; Carlsson, C.; Howell, J.A. Terrestrial laser scanning for use in virtual outcrop geology. Photogramm. Rec. 2010, 25, 225-239. [CrossRef]

5. Rarity, F.; van Lanen, X.M.T.; Hodgetts, D.; Gawthorpe, R.L.; Wilson, P.; Fabuel-Perez, I.; Redfern, J. LiDAR-based digital outcrops for sedimentological analysis: Workflows and techniques. GSL Spec. Pub. 2014, 387, 153-183. [CrossRef]

6. Goetz, A.F.H.; Vane, G.; Solomon, J.E.; Rock, B.N. Imaging Spectrometry for Earth Remote-Sensing. Science 1985, 228, 1147-1153. [CrossRef] [PubMed]

7. Goetz, A.F.H. Three decades of hyperspectral remote sensing of the Earth: A personal view. Remote Sens. Environ. 2009, 113, S5-S16. [CrossRef]

8. Kruse, F.A. Use of Airborne Imaging Spectrometer Data to Map Minerals Associated with Hydrothermally Altered Rocks in the Northern Grapevine Mountains, Nevada, and California. Remote Sens. Environ. 1988, 24, 31-51. [CrossRef]

9. Kirkland, L.; Herr, K.; Keim, E.; Adams, P.; Salisbury, J.; Hackwell, J.; Treiman, A. First use of an airborne thermal infrared hyperspectral scanner for compositional mapping. Remote Sens. Environ. 2002, 80, 447-459. [CrossRef]

10. Jones, S.; Herrmann, W.; Gemmell, J.B. Short Wavelength Infrared Spectral Characteristics of the HW Horizon: Implications for Exploration in the Myra Falls Volcanic-Hosted Massive Sulfide Camp, Vancouver Island, British Columbia, Canada. Econ. Geol. 2005, 100, 273-294. [CrossRef]

11. Van der Meer, F.D.; van der Werff, H.M.A.; van Ruitenbeek, F.J.A.; Hecker, C.A.; Bakker, W.H.; Noomen, M.F.; van der Meijde, M.; Carranza, E.J.M.; de Smeth, J.B.; Woldai, T. Multi- and hyperspectral geologic remote sensing: A review. Int. J. Appl. Earth Obs. Geoinf. 2012, 14, 112-128. [CrossRef]

12. Kruse, F.A. Integrated visible and near-infrared, shortwave infrared, and longwave infrared full-range hyperspectral data analysis for geologic mapping. J. Appl. Remote Sens. 2015, 9, 096005. [CrossRef]

13. Hunt, G.R. Spectral signatures of particulate minerals in the visible and near infrared. Geophysics 1977, 42, 501-513. [CrossRef]

14. Hunt, G.R. Near-infrared (1.3-2.4) $\mu \mathrm{m}$ spectra of alteration minerals-Potential for use in remote sensing. Geophysics 1979, 44, 1974-1986. [CrossRef]

15. Clark, R.N.; King, T.V.V.; Klejwa, M.; Swayze, G.A.; Vergo, N. High spectral resolution reflectance spectroscopy of minerals. J. Geophys. Res. 1990, 95, 12653-12680. [CrossRef] 
16. Salisbury, J.W.; Walter, L.S.; Vergo, N.; D'Aria, D.M. Infrared (2.1-2.5 $\mu \mathrm{m}$ ) Spectra of Minerals; John Hopkins University Press: Baltimore, MD, USA, 1991.

17. Baldridge, A.M.; Hook, S.J.; Grove, C.I.; Rivera, G. The ASTER spectral library version 2.0. Remote Sens. Environ. 2009, 113, 711-715. [CrossRef]

18. Laukamp, C. Short Wave Infrared Functional Groups of Rock-Forming Minerals; CSIRO, Report number EP115222; CSIRO: Canberra, Australia, 2011; pp. 1-20.

19. Kokaly, R.F.; Clark, R.N.; Swayze, G.A.; Livo, K.E.; Hoefen, T.M.; Pearson, N.C.; Wise, R.A.; Benzel, W.M.; Lowers, H.A.; Driscoll, R.L.; et al. USGS Spectral Library Version 7; U.S. Geological Survey Data Series; United States Geological Survey: Reston, VA, USA, 2017; Volume 1035, 61p. [CrossRef]

20. Kurz, T.H.; Buckley, S.J.; Howell, J.A.; Schneider, D. Integration of panoramic hyperspectral imaging with terrestrial lidar data. Photogramm. Rec. 2011, 26, 212-228. [CrossRef]

21. Kurz, T.H.; Buckley, S.J.; Howell, J.A. Close-range hyperspectral imaging for geological field studies: Workflow and methods. Int. J. Remote Sens. 2013, 34, 1798-1822. [CrossRef]

22. Buckley, S.J.; Kurz, T.H.; Howell, J.A.; Schneider, D. Terrestrial lidar and hyperspectral data fusion products for geological outcrop analysis. Comput. Geosci. 2013, 54, 249-258. [CrossRef]

23. Kurz, T.H.; Buckley, S.J. A review of hyperspectral imaging in close range applications. Int. Arch. Photogramm. Remote Sens. Spat. Inf. Sci. 2016, XLI-B5, 865-870. [CrossRef]

24. Lorenz, S.; Salehi, S.; Kirsch, M.; Zimmermann, R.; Unger, G.; Vest Sørensen, E.; Gloaguen, R. Radiometric Correction and 3D Integration of Long-Range Ground-Based Hyperspectral Imagery for Mineral Exploration of Vertical Outcrops. Remote Sens. 2018, 10, 176. [CrossRef]

25. Salehi, S.; Lorenz, S.; Vest Sørensen, E.; Zimmermann, R.; Fensholt, R.; Henning Heincke, B.; Kirsch, M.; Gloaguen, R. Integration of Vessel-Based Hyperspectral Scanning and 3D-Photogrammetry for Mobile Mapping of Steep Coastal Cliffs in the Arctic. Remote Sens. 2018, 10, 175. [CrossRef]

26. Hunt, G.J.; Salisbury, J.W. Visible and Near-Infrared Spectra of Minerals and Rocks. I. Silicate Minerals. Mod. Geol. 1970, 1, 283-300.

27. Salisbury, J.W.; D'Aria, D.M. Emissivity of terrestrial materials in the $8-14 \mu \mathrm{m}$ atmospheric window. Remote Sens. Environ. 1992, 42, 83-106. [CrossRef]

28. Hecker, C.; van der Meijde, M.; van der Meer, F.D. Thermal infrared spectroscopy on feldspars-Successes, limitations and their implications for remote sensing. ESR 2010, 103, 60-70. [CrossRef]

29. Hecker, C.; Hook, S.; Meijde, M.V.D.; Bakker, W.; Werff, H.V.D.; Wilbrink, H.; Ruitenbeek, F.V.; de Smeth, B.; Meer, F.V.D. Thermal Infrared Spectrometer for Earth Science Remote Sensing Applications-Instrument Modifications and Measurement Procedures. Sensors 2011, 11, 10981-10999. [CrossRef] [PubMed]

30. Hecker, C.; Dilles, J.H.; van der Meijde, M.; van der Meer, F.D. Thermal infrared spectroscopy and partial least squares regression to determine mineral modes of granitoid rocks. Geochem. Geophys. Geosyst. 2012, 13, Q03021. [CrossRef]

31. Eisele, A.; Chabrillat, S.; Hecker, C.; Hewson, R.; Lau, I.C.; Rogass, C.; Segl, K.; Cudahy, T.J.; Udelhoven, T.; Hostert, P.; et al. Advantages using the thermal infrared (TIR) to detect and quantify semi-arid soil properties. Remote Sens. Environ. 2015, 163, 296-311. [CrossRef]

32. Green, D.; Schodlok, M.; Green, D.; Schodlok, M. Characterisation of carbonate minerals from hyperspectral TIR scanning using features at 14000 and 11300 nm. Aust. J. Earth Sci. 2016, 1-8. [CrossRef]

33. Vaughan, R.G.; Calvin, W.M.; Taranik, J.V. SEBASS hyperspectral thermal infrared data: Surface emissivity measurement and mineral mapping. Remote Sens. Environ. 2003, 85, 48-63. [CrossRef]

34. Riley, D.N.; Hecker, C.A. Mineral Mapping with Airborne Hyperspectral Thermal Infrared Remote Sensing at Cuprite, Nevada, USA. In Thermal Infrared Remote Sensing; Remote Sensing and Digital Image Processing; Springer: Dordrecht, The Netherlands, 2013; Volume 17, pp. 495-514. [CrossRef]

35. Weksler, S.; Notesco, G.; Ben-Dor, E. An automated procedure for reducing atmospheric features and emphasizing surface emissivity in hyperspectral longwave infrared (LWIR) images. Int. J. Remote Sens. 2017, 38, 4481-4493. [CrossRef]

36. Vitins, I.; Felix, H.; Eisele, A.; Hueni, A.; Hewson, R.D. Pit-wall face mapping of carbonate mixtures using LWIR remote sensing. In Proceedings of the 10th EARSeL SIG Imaging Spectroscopy Workshop, University of Zurich, Zurich, Switzerland, 19-21 April 2017. 
37. Kirsch, M.; Lorenz, S.; Zimmermann, R.; Möckel, R.; Khodadadzadeh, M.; Tusa, L.; Chamberland, M.; Gloaguen, R. Terrestrial long-wave infrared hyperspectral imaging for geological mapping: A case study. Geophys. Res. Abstr. 2018, 20, EGU2018-10262.

38. McDowell, M.; Kruse, F.A. Enhanced Compositional Mapping through Integrated Full-Range Spectral Analysis. Remote Sens. 2016, 8, 757. [CrossRef]

39. Notesco, G.; Kopačková, V.; Rojík, P.; Schwartz, G.; Livne, I.; Dor, E. Mineral Classification of Land Surface Using Multispectral LWIR and Hyperspectral SWIR Remote-Sensing Data. A Case Study over the Sokolov Lignite Open-Pit Mines, the Czech Republic. Remote Sens. 2014, 6, 7005-7025. [CrossRef]

40. Notesco, G.; Ogen, Y.; Ben-Dor, E. Integration of Hyperspectral Shortwave and Longwave Infrared Remote-Sensing Data for Mineral Mapping of Makhtesh Ramon in Israel. Remote Sens. 2016, 8, 318. [CrossRef]

41. Harris, J.R.; Rogge, D.; Hitchcock, R.; Ijewliw, O.; Wright, D. Mapping lithology in Canada's Arctic: Application of hyperspectral data using the minimum noise fraction transformation and matched filtering. Can. J. Earth Sci. 2005, 42, 2173-2193. [CrossRef]

42. Bellian, J.A.; Beck, R.; Kerans, C. Analysis of hyperspectral and lidar data: Remote optical mineralogy and fracture identification. Geosphere 2007, 3, 491-500. [CrossRef]

43. Jakob, S.; Zimmermann, R.; Gloaguen, R. The Need for Accurate Geometric and Radiometric Corrections of Drone-Borne Hyperspectral Data for Mineral Exploration: MEPHySTo-A Toolbox for Pre-Processing Drone-Borne Hyperspectral Data. Remote Sens. 2017, 9, 88. [CrossRef]

44. Jackisch, R.; Lorenz, S.; Zimmermann, R.; Möckel, R.; Gloaguen, R. Drone-Borne Hyperspectral Monitoring of Acid Mine Drainage: An Example from the Sokolov Lignite District. Remote Sens. 2018, 10, 385. [CrossRef]

45. Bellian, J.A.; Kerans, C.; Jennette, D.C. Digital Outcrop Models: Applications of Terrestrial Scanning Lidar Technology in Stratigraphic Modeling. JSR 2005, 75, 166-176. [CrossRef]

46. Buckley, S.J.; Howell, J.A.; Enge, H.D.; Kurz, T.H. Terrestrial laser scanning in geology: Data acquisition, processing and accuracy considerations. J. Geol. Soc. Lond. 2008, 165, 625-638. [CrossRef]

47. Heritage, G.L.; Large, A.R.G. Laser Scanning for the Environmental Sciences; Heritage, G.L., Large, A.R.G., Eds.; Wiley-Blackwell: Oxford, UK, 2009.

48. James, M.R.; Robson, S. Straightforward reconstruction of 3D surfaces and topography with a camera: Accuracy and geoscience application. J. Geophys. Res. Earth Surf. 2012, 117, F03017. [CrossRef]

49. James, M.R.; Robson, S. Mitigating systematic error in topographic models derived from UAV and ground-based image networks. Earth Surf. Process. Landf. 2014, 39, 1413-1420. [CrossRef]

50. Westoby, M.J.; Brasington, J.; Glasser, N.F.; Hambrey, M.J.; Reynolds, J.M. "Structure-from-Motion" photogrammetry: A low-cost, effective tool for geoscience applications. Geomorphology 2012, 179, 300-314. [CrossRef]

51. Bemis, S.P.; Micklethwaite, S.; Turner, D.; James, M.R.; Akciz, S.; Thiele, S.T.; Bangash, H.A. Ground-based and UAV-Based photogrammetry: A multi-scale, high- resolution mapping tool for structural geology and paleoseismology. J. Struct. Geol. 2014, 69, 163-178. [CrossRef]

52. Eltner, A.; Kaiser, A.; Castillo, C.; Rock, G.; Neugirg, F.; Abellán, A. Image-based surface reconstruction in geomorphometry-Merits, limits and developments of a promising tool for geoscientists. Earth Surf. Dynam. Discuss. 2015, 3, 1445-1508. [CrossRef]

53. Murphy, R.J.; Monteiro, S.T.; Schneider, S. Evaluating Classification Techniques for Mapping Vertical Geology Using Field-Based Hyperspectral Sensors. IEEE Trans. Geosci. Remote Sens. 2012, 50, 3066-3080. [CrossRef]

54. Murphy, R.J.; Monteiro, S.T. Mapping the distribution of ferric iron minerals on a vertical mine face using derivative analysis of hyperspectral imagery (430-970nm). ISPRS J. Photogramm. Remote Sens. 2013, 75, $29-39$. [CrossRef]

55. Wilkinson, M.W.; Jones, R.R.; Woods, C.E.; Gilment, S.R.; McCaffrey, K.J.W.; Kokkalas, S.; Long, J.J. A comparison of terrestrial laser scanning and structure-from-motion photogrammetry as methods for digital outcrop acquisition. Geosphere 2016, 12, 1865-1880. [CrossRef]

56. Cawood, A.J.; Bond, C.E.; Howell, J.A.; Butler, R.W.H.; Totake, Y. LiDAR, UAV or compass-clinometer? Accuracy, coverage and the effects on structural models. J. Struct. Geol. 2017, 98, 67-82. [CrossRef]

57. James, M.R.; Robson, S.; d'Oleire-Oltmanns, S.; Niethammer, U. Optimising UAV topographic surveys processed with structure-from-motion: Ground control quality, quantity and bundle adjustment. Geomorphology 2017, 280, 51-66. [CrossRef] 
58. Kruse, F.A.; Bedell, R.L.; Taranik, J.V.; Peppin, W.A.; Weatherbee, O.; Calvin, W.M. Mapping alteration minerals at prospect, outcrop and drill core scales using imaging spectrometry. Int. J. Remote Sens. 2012, 33, 1780-1798. [CrossRef] [PubMed]

59. Spinetti, C.; Mazzarini, F.; Casacchia, R.; Colini, L.; Neri, M.; Behncke, B.; Salvatori, R.; Buongiorno, M.F.; Pareschi, M.T. Spectral properties of volcanic materials from hyperspectral field and satellite data compared with LiDAR data at Mt. Etna. Int. J. Appl. Earth Obs. Geoinf. 2009, 11, 142-155. [CrossRef]

60. Kereszturi, G.; Schaefer, L.N.; Schleiffarth, W.K.; Procter, J.; Pullanagari, R.R.; Mead, S.; Kennedy, B. Integrating airborne hyperspectral imagery and LiDAR for volcano mapping and monitoring through image classification. Int. J. Appl. Earth Obs. Geoinf. 2018, 73, 323-339. [CrossRef]

61. Van der Meer, F.; Kopačková, V.; Koucká, L.; van der Werff, H.M.A.; van Ruitenbeek, F.J.A.; Bakker, W.H. Wavelength feature mapping as a proxy to mineral chemistry for investigating geologic systems: An example from the Rodalquilar epithermal system. Int. J. Appl. Earth Obs. Geoinf. 2018, 64, 237-248. [CrossRef]

62. Murphy, R.J.; Taylor, Z.; Schneider, S.; Nieto, J. Mapping clay minerals in an open-pit mine using hyperspectral and LiDAR data. Eur. J. Remote Sens. 2015, 48, 511-526. [CrossRef]

63. Kroner, U.; Romer, R.L. Two plates-Many subduction zones: The Variscan orogeny reconsidered. Gondwana Res. 2013, 24, 298-329. [CrossRef]

64. Tichomirowa, M. 207Pb/206Pb-Einzelzirkondatierungen zur Bestimmung des Intrusionsalters des Niederbobritzscher Granites. Terra Nostra 1997, 8, 183-184.

65. Förster, H.-J.; Tischendorf, G.; Trumbull, R.B.; Gottesmann, B. Late-Collisional Granites in the Variscan Erzgebirge, Germany. J. Pet. 1999, 40, 1613-1645. [CrossRef]

66. Müller, H. Die Erzgänge des Freiberger Bergrevieres—Erläuterungen zur geololgischen Specialkarte des Königreichs Sachsen; Königliches Finanzministerium: Leipzig, Germany, 1901; 366p.

67. Rösler, H.J.; Pilot, J.; Starke, R.; Schreiter, E. Die Vererzungen im Granit von Niederbobritzsch bei Freiberg. Abh. Staatl. Mus. Miner. Geol. Dresd. 1990, 37, 103-123.

68. Seifert, T.; Sandmann, D. Mineralogy and geochemistry of indium-bearing polymetallic vein-type deposits: Implications for host minerals from the Freiberg district, Eastern Erzgebirge, Germany. Ore Geol. Rev. 2006, 28, 1-31. [CrossRef]

69. Kamb, W.B. Ice Petrofabric Observations from Blue Glacier, Washington, in Relation to Theory and Experiment. J. Geophys. Res. 1959, 64, 1891-1909. [CrossRef]

70. AisaFENIX Hyperspectral Sensor. 2018. Available online: http://www.specim.fi/products/aisafenixhyperspectral-sensor/ (accessed on 18 August 2018).

71. Spectralon Technical Datashet-Reflectance Materials and Coatings; Technical Guide; Labsphere: North Sutton, NH, USA, 2016; pp. 1-26.

72. Green, A.A.; Berman, M.; Switzer, P.; Craig, M.D. A Transformation for Ordering Multispectral Data in Terms of Image Quality with Implications for Noise Removal. IEEE Trans. Geosci. Remote Sens. 1988, 26, 65-74. [CrossRef]

73. Pontual, S.; Merry, N.; Gamson, P. Spectral Analysis Guides for Mineral Exploration; AusSpec International Pty: Arrowtown, New Zealand, 1997; Volumes 1-7.

74. Crowley, J.K.; Williams, D.E.; Hammarstrom, J.M.; Piatak, N.; Chou, I.-M.; Mars, J.C. Spectral reflectance properties $(0.4-2.5 \mu \mathrm{m})$ of secondary Fe-oxide, Fe-hydroxide, and Fe-sulphate-hydrate minerals associated with sulphide-bearing mine wastes. Geochem. Explor. Environ. Anal. 2003, 3, 219-228. [CrossRef]

75. Bakker, W.H.; van Ruitenbeek, F.J.A.; van der Werff, H.M.A.; Zegers, T.E.; Oosthoek, J.H.P.; Marsh, S.H.; van der Meer, F.D. Processing OMEGA/Mars Express hyperspectral imagery from radiance-at-sensor to surface reflectance. Planet. Space Sci. 2014, 90, 1-9. [CrossRef]

76. Van der Meer, F. Analysis of spectral absorption features in hyperspectral imagery. Int. J. Appl. Earth Obs. Geoinf. 2004, 5, 55-68. [CrossRef]

77. Boardman, J.W.; Kruse, F.A.; Green, R.O. Mapping target signatures via partial unmixing of AVIRIS data. In Proceedings of the Fifth JPL Airborne Earth Science Workshop, Pasadena, CA, USA, 23-26 January 1995; pp. 95-101.

78. Heylen, R.; Scheunders, P. Multidimensional Pixel Purity Index for Convex Hull Estimation and Endmember Extraction. IEEE Trans. Geosci. Remote Sens. 2013, 51, 4059-4069. [CrossRef] 
79. Winter, M.E. N-FINDR: An algorithm for fast autonomous spectral end-member determination in hyperspectral data. In Proceedings of SPIE-The International Society for Optical Engineering; Descour, M.R., Shen, S.S., Eds.; University of Queensland: Brisbane, Australia, 1999; Volume 3753, pp. 266-275.

80. Kruse, F.A.; Lefkoff, A.B.; Boardman, J.W.; Heidebrecht, K.B.; Shapiro, A.T.; Barloon, P.J.; Goetz, A.F.H. The spectral image processing system (SIPS) - Interactive visualization and analysis of imaging spectrometer data. Remote Sens. Environ. 1993, 44, 145-163. [CrossRef]

81. Telops Hyperspectral IR Cameras. 2018. Available online: http://telops.com/products/hyperspectralcameras (accessed on 18 August 2018).

82. Schlerf, M.; Rock, G.; Lagueux, P.; Ronellenfitsch, F.; Gerhards, M.; Hoffmann, L.; Udelhoven, T. A Hyperspectral Thermal Infrared Imaging Instrument for Natural Resources Applications. Remote Sens. 2012, 4, 3995-4009. [CrossRef]

83. Boardman, J.W. Sedimentary Facies Analysis Using Imaging Spectrometry: A Geophysical Inverse Problem. Ph.D. Thesis, University of Colorado, Boulder, CO, USA, 1991.

84. Adams, J.B.; Smith, M.O.; Gillespie, A.R. Imaging spectroscopy: Interpretation based on spectral mixture analysis. In Remote Geochemical Analysis Elemental and Mineralogical Composition; Pieters, C.M., Englert, P.A., Eds.; Cambridge Univ. Press: Cambridge, UK, 1993; pp. 145-166, ISBN 9780521402811.

85. Li, H.C.; Chang, C.I. Linear spectral unmixing using least squares error, orthogonal projection and simplex volume for hyperspectral images. In Proceedings of the 7th Workshop on Hyperspectral Image and Signal Processing: Evolution in Remote Sensing (WHISPERS), Tokyo, Japan, 2-5 June 2015; pp. 1-4.

86. Liaw, A.; Wiener, M. Classification and Regression by randomForest. R News 2002, 2, 18-22.

87. Silván-Cárdenas, J.L.; Wang, L. Fully Constrained Linear Spectral Unmixing: Analytic Solution Using Fuzzy Sets. IEEE Trans. Geosci. Remote Sens. 2010, 48, 3992-4002. [CrossRef]

88. Optronics Hyperspectral-The RIKOLA Product Range. 2018. Available online: http://senop.fi/en/ optronics-hyperspectral (accessed on 18 August 2018).

89. Aibot X6-Robust and Reliable UAV Solution. 2018. Available online: https://leica-geosystems.com/en$\mathrm{gb} /$ products/uav-systems/aibot-x6 (accessed on 18 August 2018).

90. Savitzky, A.; Golay, M.J.E. Smoothing and Differentiation of Data by Simplified Least Squares Procedures. Anal. Chem. 1964, 36, 1627-1639. [CrossRef]

91. Sensefly eBee Classic. 2018. Available online: https://www.sensefly.com/drone/ebee-mapping-drone/ (accessed on 18 August 2018).

92. Carrivick, J.L.; Smith, M.W.; Quincey, D.J. Structure from Motion in the Geosciences; Wiley-Blackwell: Hoboken, NJ, USA, 2016; ISBN 9781118895849.

93. Doebelin, N.; Kleeberg, R. IUCr Profex: A graphical user interface for the Rietveld refinement program BGMN. J. Appl. Crystallogr. 2015, 48, 1573-1580. [CrossRef] [PubMed]

94. Vernon, R.H. Crystallization and hybridism in microgranitoid enclave magmas: Microstructural evidence. J. Geophys. Res. Solid Earth 1990, 95, 17849-17859. [CrossRef]

95. Hibbard, M.J. Textural anatomy of twelve magma-mixed granitoid systems. In Enclaves and Granite Petrology, Developments in Petrology 13; Didier, J., Barbarin, B., Eds.; Elsevier Science: Amsterdam, The Netherlands, 1991; pp. 431-444.

96. Rösler, H.J.; Bothe, M. Bemerkungen zur Petrologie des Granites von Niederbobritzsch bei Freiberg und zur Bildung der Allanite. Abh. Staat. Mus. Mineral. Geol. Dresd. 1990, 37, 73-101.

97. Rösler, H.J.; Budzinski, H. Das Bauprinzip des Granits von Niederbobritzsch bei Freiberg/Sa. auf Grund seiner geochemischen Analyse. Z. Geol. Wiss. 1994, 22, 307-324.

98. Whitney, D.L.; Evans, B.W. Abbreviations for names of rock-forming minerals. Am. Miner. 2010, 95, $185-187$. [CrossRef]

99. Post, J.L.; Noble, P.N. The Near-Infrared Combination Band Frequencies of Dioctahedral Smectites, Micas, and Illites. Clays Clay Miner. 1993, 41, 639-644. [CrossRef]

100. Herrmann, W.; Blake, M.; Doyle, M.; Huston, D.; Kamprad, J.; Merry, N.; Pontual, S. Short Wavelength Infrared (SWIR) Spectral Analysis of Hydrothermal Alteration Zones Associated with Base Metal Sulfide Depositsat Rosebery and Western Tharsis, Tasmania, and Highway-Reward, Queensland. Econ. Geol. 2001, 96, 939-955. [CrossRef]

101. Dalm, M.; Buxton, M.W.N.; van Ruitenbeek, F.J.A.; Voncken, J.H.L. Application of near-infrared spectroscopy to sensor based sorting of a porphyry copper ore. Miner. Eng. 2014, 58, 7-16. [CrossRef] 
102. Yang, K.; Huntington, J.F.; Scott, K.M.; Mason, P. Alteration Zoning in the Volcanic Rocks at Hishikari, Japan, as Revealed by Short Wavelength Infrared Spectroscopy; Exploration and Mining Report 203R, CSIRO/AMIRA Project P435-Mineral Mapping with Field Spectroscopy for Exploration; CSIRO Division of Exploration and Mining, Institute of Minerals, Energy and Construction: Canberra, Australia, 1996.

103. Scott, K.M.; Yang, K. Spectral Reflectance Studies of White Micas; Exploration and Mining Report 439R, CSIRO/AMIRA Project P435-Mineral Mapping with Field Spectroscopy for Exploration; CSIRO Division of Exploration and Mining, Institute of Minerals, Energy and Construction: Canberra, Australia, 1997.

104. Fukuchi, R.; Fujimoto, K.; Kameda, J.; Hamahashi, M.; Yamaguchi, A.; Kimura, G.; Hamada, Y.; Hashimoto, Y.; Kitamura, Y.; Saito, S. Changes in illite crystallinity within an ancient tectonic boundary thrust caused by thermal, mechanical, and hydrothermal effects: An example from the Nobeoka Thrust, southwest Japan. Earth Planet Space 2014, 66, 116. [CrossRef]

105. Hunt, G.R.; Ashley, R.P. Spectra of altered rocks in the visible and near infrared. Econ. Geol. 1979, 74, 1613-1629. [CrossRef]

106. Morris, R.V.; Lauer, H.V., Jr.; Lawson, C.A.; Gibson, E.K., Jr.; Nace, G.A.; Stewart, C. Spectral and other physicochemical properties of submicron powders of hematite $\left(\alpha-\mathrm{Fe}_{2} \mathrm{O}_{3}\right)$, maghemite $\left(\gamma-\mathrm{Fe}_{2} \mathrm{O}_{3}\right)$, magnetite $\left(\mathrm{Fe}_{3} \mathrm{O}_{4}\right)$, goethite $(\alpha-\mathrm{FeOOH})$, and lepidocrocite $(\gamma-\mathrm{FeOOH})$. J. Geophys. Res. 1985, 90, 3126-3144. [CrossRef] [PubMed]

107. Townsend, T.E. Discrimination of iron alteration minerals in visible and near-infrared reflectance data. J. Geophys. Res. Solid Earth 1987, 92, 1441-1454. [CrossRef]

108. Bishop, J.L. The visible and infrared spectral properties of jarosite and alunite. Am. Miner. 2005, 90, 1100-1107. [CrossRef]

109. Photogrammetric and VNIR-SWIR-LWIR Hyperspectral Data Integration for Geological Mapping; Case Study Naundorf Quarry; Helmholtz-Zentrum Dresden-Rossendorf: Dresden, Germany, 2018. Available online: https:/ /www. hzdr.de/FWG/FWGE/Hyperclouds/KirschEtAl_Naundorf_RGB-VNIR-SWIR-LWIR.html (accessed on 19 August 2018).

110. Schütz, M. Potree: Rendering Large Point Clouds in Web Browsers. Diploma Thesis, Technische Universität Wien, Vienna, Austria, 2016.

111. Murphy, R.J.; Schneider, S.; Monteiro, S.T. Consistency of measurements of wavelength position from hyperspectral imagery: Use of the ferric iron crystal field absorption at $\sim 900 \mathrm{~nm}$ as an Indicator of Mineralogy. IEEE Trans. Geosci. Remote Sens. 2014, 52, 2843-2857. [CrossRef]

112. Bladh, K.W. The formation of goethite, jarosite, and alunite during the weathering of sulfide-bearing felsic rocks. Econ. Geol. 1982, 77, 176-184. [CrossRef]

113. Clark, R.N. Spectroscopy of Rocks and Minerals, and Principles of Spectroscopy. In The Manual of Remote Sensing, Remote Sensing for the Earth Sciences, 3rd ed.; Rencz, A.N., Ryerson, R.A., Eds.; John Wiley \& Sons, Inc.: Hoboken, NJ, USA, 1999; Volume 3, pp. 1-50, ISBN 978-0-471-29405-4.

114. Turner, D.J.; Rivard, B.; Groat, L.A. Visible and short-wave infrared reflectance spectroscopy of REE fluorocarbonates. Am. Miner. 2014, 99, 1335-1346. [CrossRef]

115. Boesche, K.N.; Rogass, C.; Lubitz, C.; Brell, M.; Herrmann, S.; Mielke, C.; Tonn, S.; Appelt, O.; Altenberger, U.; Kaufmann, H. Hyperspectral REE (Rare Earth Element) Mapping of Outcrops-Applications for Neodymium Detection. Remote Sens. 2015, 7, 5160-5186. [CrossRef]

116. Kahle, A.B.; Goetz, A.F.H. Mineralogic Information from a New Airborne Thermal Infrared Multispectral Scanner. Science 1983, 222, 24-27. [CrossRef] [PubMed]

117. Thompson, A.J.B.; Hauff, P.L.; Robitaille, A.J. Alteration Mapping in Exploration: Application of Short-Wave Infrared (SWIR) Spectroscopy. In Remote Sensing and Spectral Geology; Bedell, R., Crósta, A.P., Grunsky, E., Eds.; Society of Economic Geologists: Littleton, CO, USA, 2009. [CrossRef]

118. Thiele, S.T.; Grose, L.; Samsu, A.; Micklethwaite, S.; Vollgger, S.A.; Cruden, A.R. Rapid, semi-automatic fracture and contact mapping for point clouds, images and geophysical data. Solid Earth 2017, 8, 1241-1253. [CrossRef]

119. Adão, T.; Hruška, J.; Pádua, L.; Bessa, J.; Peres, E.; Morais, R.; Sousa, J. Hyperspectral Imaging: A Review on UAV-Based Sensors, Data Processing and Applications for Agriculture and Forestry. Remote Sens. 2017, 9 , 1110. [CrossRef]

120. Khodadadzadeh, M.; Li, J.; Prasad, S.; Plaza, A. Fusion of Hyperspectral and LiDAR Remote Sens. Data Using Multiple Feature Learning. IEEE J. Sel. Top. Appl. Earth Obs. Remote Sens. 2015, 8, 2971-2983. [CrossRef] 
121. Rasti, B.; Ghamisi, P.; Gloaguen, R. Hyperspectral and LiDAR Fusion Using Extinction Profiles and Total Variation Component Analysis. IEEE Trans. Geosci. Remote Sens. 2017, 55, 3997-4007. [CrossRef]

122. Unger, G. 3D Integration of Multi-Source and Multi-Scale Exploration Data: The Example of the Paleoproterozoic Marmorilik Pb-Zn-Deposit/Central-West Greenland. Master's Thesis, Technische Universität Bergakademie Freiberg, Freiberg, Germany, 2018.

123. De Oliveira, R.A.; Khoramshahi, E.; Suomalainen, J.; Hakala, T.; Viljanen, N.; Honkavaara, E. Real-time and post-processed georeferencing for hyperspectral drone remote sensing. In Proceedings of the ISPRS TC II Mid-Term Symposium towards Photogrammetry, Riva del Garda, Italy, 3-7 June 2018; pp. 1-8.

(C) 2018 by the authors. Licensee MDPI, Basel, Switzerland. This article is an open access article distributed under the terms and conditions of the Creative Commons Attribution (CC BY) license (http://creativecommons.org/licenses/by/4.0/). 